\title{
Hypothalamic CCL2/CCR2 Chemokine System: Role in Sexually Dimorphic Effects of Maternal Ethanol Exposure on Melanin-Concentrating Hormone and Behavior in Adolescent Offspring
}

\author{
Guo-Qing Chang, Olga Karatayev, Viktoriya Halkina, Jonathan Edelstien, Estefania Ramirez, and Sarah F. Leibowitz
}

Rockefeller University, New York, New York 10065

Clinical and animal studies show that ethanol exposure and inflammation during pregnancy cause similar behavioral disturbances in the offspring. While ethanol is shown to stimulate both neuroimmune and neurochemical systems in adults, little is known about their anatomical relationship in response to ethanol in utero and whether neuroimmune factors mediate ethanol's effects on neuronal development and behavior in offspring. Here we examined in female and male adolescent rats a specific population of neurons concentrated in lateral hypothalamus, which coexpress the inflammatory chemokine C-C motif ligand 2 (CCL2) or its receptor CCR2 with the orexigenic neuropeptide, melanin-concentrating hormone $(\mathrm{MCH})$, that promotes ethanol drinking behavior. We demonstrate that maternal administration of ethanol $(2 \mathrm{~g} / \mathrm{kg} / \mathrm{d})$ from embryonic day 10 (E10) to E15, while having little impact on glia, stimulates expression of neuronal CCL2 and CCR2, increases density of both large CCL2 neurons colocalizing MCH and small CCL2 neurons surrounding MCH neurons, and stimulates ethanol drinking and anxiety in adolescent offspring. We show that these neuronal and behavioral changes are similarly produced by maternal administration of CCL2 ( 4 or $8 \mu \mathrm{g} / \mathrm{kg} / \mathrm{d}, \mathrm{E} 10-\mathrm{E} 15)$ and blocked by maternal administration of a CCR2 antagonist INCB3344 (1 mg/kg/d, E10-E15), and these effects of ethanol and CCL2 are sexually dimorphic, consistently stronger in females. These results suggest that this neuronal CCL2/CCR2 system closely linked to $\mathrm{MCH}$ neurons has a role in mediating the effects of maternal ethanol exposure on adolescent offspring and contributes to the higher levels of adolescent risk factors for alcohol use disorders described in women.

Key words: anxiety; CCR2 antagonist; ethanol drinking; lateral hypothalamus; neuroimmune; prenatal

\section{Significance Statement}

Ethanol consumption and inflammatory agents during pregnancy similarly increase alcohol intake and anxiety in adolescent offspring. To investigate how neurochemical and neuroimmune systems interact to mediate these disturbances, we examined a specific population of hypothalamic neurons coexpressing the inflammatory chemokine CCL2 and its receptor CCR2 with the neuropeptide, melanin-concentrating hormone. We demonstrate in adolescent offspring that maternal administration of CCL2, like ethanol, stimulates these neurons and increases ethanol drinking and anxiety, and these effects of ethanol are blocked by maternal CCR2 antagonist and consistently stronger in females. This suggests that neuronal chemokine signaling linked to neuropeptides mediates effects of maternal ethanol exposure on adolescent offspring and contributes to higher levels of adolescent risk factors for alcohol use disorders in women.

\section{Introduction}

Clinical studies show that alcohol consumption during pregnancy increases alcohol drinking and related behavioral distur- bances in the offspring during adolescence, when there is a surge in alcohol intake and increased risk for alcohol abuse (Baer et al., 2003; Alati et al., 2006; Malone et al., 2010; Spear and Varlinskaya, 2010). Similar behavioral effects of maternal ethanol expo- 
sure are also evident in rodents, as demonstrated by studies from this laboratory (Chang et al., 2015) and others (Chotro and Arias, 2003; March et al., 2009; Fabio et al., 2015), and are believed to result from disturbances in limbic regions of neurotransmitter and neuropeptide systems (Poon et al., 2016) and neuroinflammatory factors, such as chemokines and cytokines (Drew et al., 2015; Terasaki and Schwarz, 2016). While animal studies show ethanol to stimulate these neuroimmune and neurochemical systems in adults (Kane and Drew, 2016; Abrahao et al., 2017; Crews et al., 2017), little is known about their anatomical and functional relationship in response to ethanol in utero and the role of neuroimmune systems in mediating ethanol's actions.

To address these questions, we focused here on specific neuroimmune and neuropeptide systems concentrated in the lateral hypothalamus ( $\mathrm{LH})$, which are known to stimulate behaviors related to ethanol drinking. Neurons expressing the orexigenic peptide, melanin-concentrating hormone $(\mathrm{MCH})$, are dense in the LH (Skofitsch et al., 1985; Bittencourt et al., 1992) and highly sensitive in rats to ethanol at low-to-moderate doses, which stimulate their expression in both adults (Morganstern et al., 2010a) and offspring prenatally exposed to ethanol (Chang et al., 2015). This neuropeptide has a role in promoting ethanol consumption and anxiety-like behaviors (Duncan et al., 2005; GonzálezBurgos et al., 2006; Cippitelli et al., 2010; Morganstern et al., $2010 \mathrm{~b})$. In addition to having immunomodulatory properties in the periphery (Ziogas et al., 2014), MCH colocalizes in the LH with the inflammatory chemokine $\mathrm{C}-\mathrm{C}$ motif ligand 2 (CCL2) and its receptor CCR2 (Banisadr et al., 2005), both of which, like $\mathrm{MCH}$, are stimulated by ethanol in adult rats (Nanji et al., 2001; He and Crews, 2008; Kane et al., 2013, 2014; Pascual et al., 2015; Terasaki and Schwarz, 2016) and are positively related to ethanol intake and anxiety (Blednov et al., 2005; Pascual et al., 2014; June et al., 2015; Sawicki et al., 2015; Valenta and Gonzales, 2016). The inflammatory agent LPS during pregnancy similarly increases alcohol intake and anxiety in the offspring (Liu et al., 2004; Lin et al., 2012) and stimulates CCL2 in the periphery and brain (Rankine et al., 2006; Oskvig et al., 2012). This chemokine is believed to be a key mediator in molecular pathways positively linking the immune system to neuronal function and activity (Zhou et al., 2011; Chu et al., 2014; Cerri et al., 2016; Xie et al., 2018) and is shown in vitro to increase the density and migration of hypothalamic embryonic neurons and their expression of orexigenic peptides (Poon et al., 2014).

In our studies involving maternal intraoral administration of ethanol at low-to-moderate doses $(1-3 \mathrm{~g} / \mathrm{kg} / \mathrm{d})$ for $5 \mathrm{~d}$ from embryonic day 10 (E10) to E15 (Chang et al., 2012, 2015), we found in male offspring at different ages that ethanol stimulates neurogenesis in the LH while having little impact on gliogenesis or apoptosis and increases the genesis and density of CCR2 neurons that colocalize $\mathrm{MCH}$, while also promoting consumption of ethanol. Our goals here are to investigate more closely the CCL2/ CCR2 system in the LH: (1) as it relates to the dense population of $\mathrm{MCH}$ neurons after in utero exposure to ethanol; and (2) as it functions in mediating ethanol's effects on neuronal development and adolescent behavior. Our results demonstrate that maternal ethanol exposure profoundly affects fetal programming of these $\mathrm{MCH}$ neurons and ethanol drinking behavior in adolescent offspring and provide evidence that the CCL2/CCR2 chemokine

Correspondence should be addressed to Dr. Sarah F. Leibowitz, Laboratory of Behavioral Neurobiology, Rockefeller University, 1230 York Avenue, New York, NY 10065. E-mail: leibow@rockefeller.edu.

DOI:10.1523/JNEUROSCI.0637-18.2018

Copyright $\odot 2018$ the authors $\quad 0270-6474 / 18 / 389073-19 \$ 15.00 / 0$ system in the LH mediates these neuronal and behavioral effects of ethanol and is more sensitive in females than males to both ethanol and chemokine stimulation.

\section{Materials and Methods}

All procedures were conducted in a fully accredited Association for Assessment and Accreditation of Laboratory Animal Care facility $\left(22^{\circ} \mathrm{C}\right.$, 12:12 h light-dark cycle with lights off at 8:00 A.M.), in accordance with protocols approved by the Rockefeller University Animal Care and Use Committee and consistent with the National Institutes of Health Guide to the care and use of laboratory animals.

\section{Animals}

Time-pregnant, Sprague Dawley rats (220-240 g) (Charles River) arrived at the facility on embryonic day 5 (E5) and were acclimated to laboratory conditions until E10, at which time experiments began as described in detail below. At birth, on postnatal day 0 (P0), litters were culled to $n=8$, and both female and male offspring were tested, with 1 male and 1 female pup taken from each litter and the number of offspring/sex/group ( $n=7-10)$ equal to the number of litters/group. In all experiments, rodent chow (LabDiet Rodent Chow 5001) and filtered water were available ad libitum. Starting at weaning (P21), food and water intake was measured 3 times per week and body weight weekly. The female and male offspring were examined at the start of puberty, which is P35 for females and P40 for males (Sengupta, 2013; Greco et al., 2015; Gillette et al., 2017). We chose to study puberty onset, which is a critical age when there is a spontaneous surge in ethanol consumption in humans and rodents (Spear and Varlinskaya, 2010), the effects of prenatal ethanol exposure are most prominent (Cornelius et al., 2016), and there is increased risk for alcohol abuse and possible sex differences in humans (Patton et al., 2004; Witt, 2007; Foster et al., 2015).

\section{Maternal administration of ethanol}

Pregnant (E10) dams ( $n=7-10$ /experiment) were intraorally administered, from E10-E15 when neuronal development is greatest in the LH (Brischoux et al., 2001), either a $2 \mathrm{~g} / \mathrm{kg} / \mathrm{d}$ ethanol solution $(30 \% \mathrm{v} / \mathrm{v}$ ) or a control solution of maltose-dextrin made isocaloric to the ethanol solution (Chang et al., 2012), with an additional group of pregnant rats assigned as untreated controls. The daily dose of ethanol was split in half with all rats gavaged twice daily, with the first gavage occurring $2 \mathrm{~h}$ after start of the dark cycle and the second gavage occurring $7 \mathrm{~h}$ later. In blood collected from the tail vein at $2 \mathrm{~h}$ after the first ethanol gavage on E11, blood ethanol concentration (BEC) was measured using Analox GM7 Alcohol Analyzer and was elevated to $\sim 80 \mathrm{mg} \%$, consistent with previous reports (Qiang et al., 2002; Chang et al., 2012). There were no differences between the untreated, control, and ethanol-treated groups, in terms of the dam's body weight (245-265 g) and chow intake (60-80 $\mathrm{kcal} / \mathrm{d})$, the size (9-15) and body weight (5.7-6.8 g) of their litters with no spontaneous abortions, and the body weights of the female offspring at P35 (125-175 g) and male offspring at P40 (168-215 g).

\section{Maternal administration of CCL2}

Building on our results here showing maternal ethanol administration to markedly increase CCL2 expression and cell density and to cause an unusually large increase in its receptor CCR2 in the offspring brain, our next goal was to determine whether maternal administration of CCL2 itself, the primary ligand of CCR2, has the same effects as ethanol on both the brain and behavior of the offspring. With no studies to date involving administration of CCL2 to pregnant rats and examining its impact on the offspring, we first tested the effect of CCL2 injection in nonpregnant females to determine whether it has any adverse effects on their pregnancy, daily food and water intake, and also whether it stimulates the gene expression of $\mathrm{MCH}$ in the LH. Nonpregnant female rats $(n=$ 4/group) received at $4 \mathrm{~h}$ after dark onset a single subcutaneous injection of the vehicle (sterile water) or CCL2 at 4 or $8 \mu \mathrm{g} / \mathrm{kg}$, doses used in prior rat studies of inflammation and pain (Dansereau et al., 2008; Qin et al., 2008); and in addition to their $24 \mathrm{~h}$ food and water intake, we measured after death at $2 \mathrm{~h}$ after injection the expression of $\mathrm{MCH}$ in the $\mathrm{LH}$. Analysis of the data using a one-way ANOVA, while showing no main 


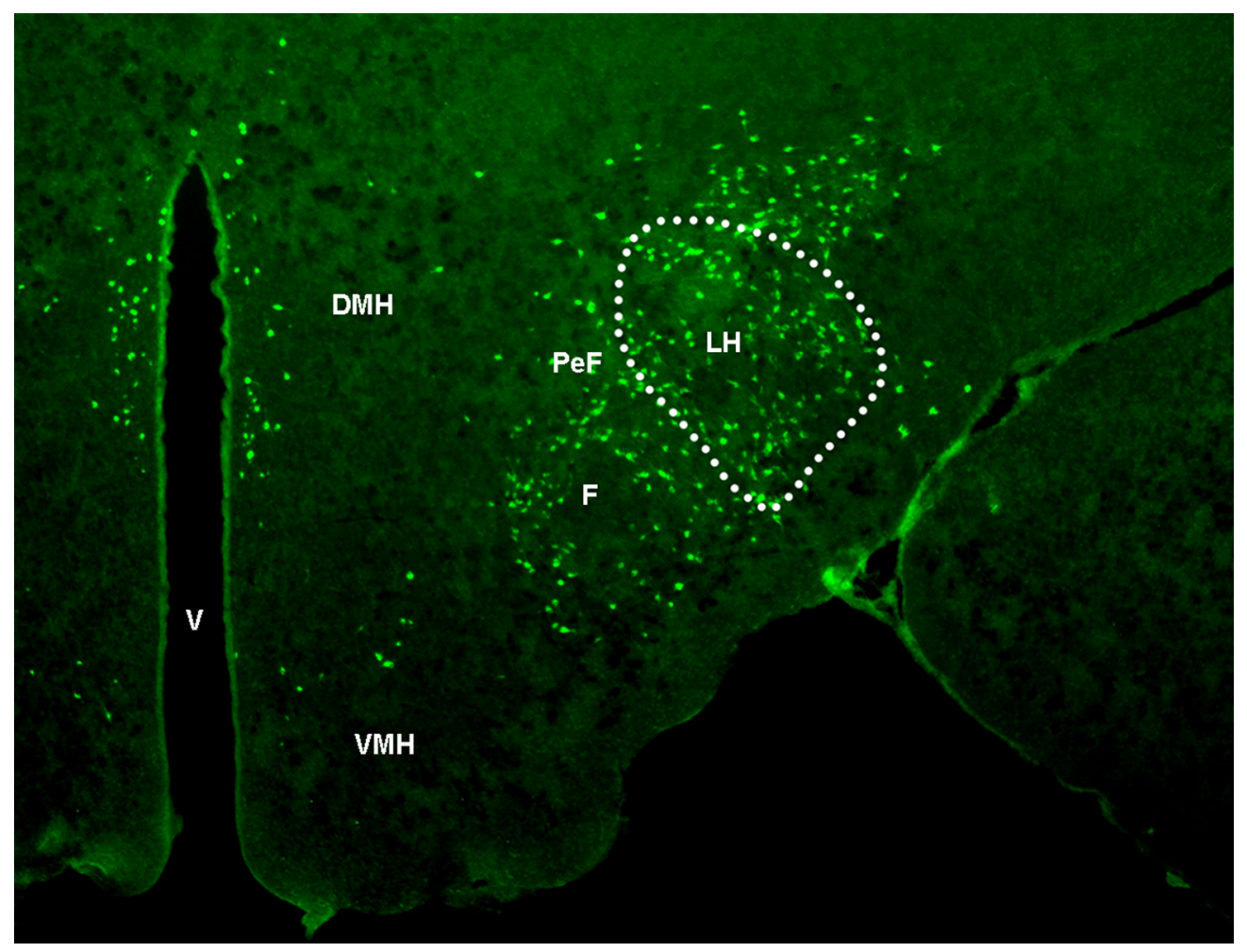

Figure 1. Representative photomicrograph illustrates, at low magnification $(2.5 \times)$ and anterior-posterior level of bregma -3.12 (Paxinos and Watson, 2005), the LH area and MCH-labeled neurons within it (outlined by dotted line) that were examined in this study. PeF, Perifornical hypothalamus; F, fornix; V, ventricle; DMH, dorsomedial hypothalamus; VMH, ventromedial hypothalamus.

effect of treatment on their food intake $\left(F_{(2,18)}=3.25, p=0.562 ; 65 \pm\right.$ $8.2 \mathrm{vs} 72 \pm 9.1 \mathrm{kcal} / \mathrm{d})$ or water intake $\left(F_{(2,18)}=2.89, p=0.741 ; 20 \pm 4\right.$ vs $18 \pm 5 \mathrm{ml} / \mathrm{d}$ ), showed, as with ethanol, a significant main effect of treatment on $\mathrm{MCH}$ mRNA levels in the LH of these adult nonpregnant rats $\left(F_{(2,18)}=6.89, p=0.0361\right)$, which reflected a significant increase $(25 \%, p=0.0251)$ after CCL2 administration similarly at both doses. Building on this result, we then injected for the main experiment these two doses of CCL2 ( 4 and $8 \mu \mathrm{g} / \mathrm{kg}$, s.c.) daily into pregnant rats, from E10 to E15 at $4 \mathrm{~h}$ into the dark cycle, and examined their effects compared with vehicle control on the brain and behavior of the adolescent offspring.

\section{$q R T-P C R$}

Rats were killed at P35 for females and P40 for males, their brains were removed, and the LH was dissected. Total RNA was then extracted from each microdissected sample, cDNA was synthesized, and qRT-PCR was performed as previously described (Barson et al., 2009; Chang et al., 2012). The primers, designed with ABI Primer Express Version 3.0 software from published sequences, were as follows: (1) cyclophilin: $5^{\prime}$ AATATGATCAAGCATTGGCTGATC-3' (forward) and 5'-TTGTGC TTTTCGGTATAGTGCTTT-3' (reverse); (2) GAPDH: 5' -TGACAACT CCCTCAAGATTGTCA-3' (forward) and 5'-GGCATGGACTGTGGT CATGA-3' (reverse); (3) MCH: 5'-CAAACAGGATGGCGAAGATG A-3' (forward) and 5' -AGGCTTTCCCCATCCTGAAT-3' (reverse); (4) CCL2: 5'-GTGCTGTCTCAGCCAGATGCAGTT-3' (forward) and 5'AGTTCTCCAGCCGACTCATTGGG-3' (reverse); and (5) CCR2: 5' TACCTGTTCAACCTGGCCATCT-3' (forward) and 5' -AGACCCACT CATTTGCAGCAT- $3^{\prime}$ (reverse). Concentration of the cyclophilin, GAPDH, CCL2, and CCR2 primers was $200 \mathrm{~nm}$ and of the $\mathrm{MCH}$ primer was $50 \mathrm{~nm}$.

As previously described in our publications (Chang et al., 2008; Barson et al., 2013) and others (West et al., 2017; Adachi et al., 2018), mRNA levels of the target gene in each rat were normalized within subject relative to mRNA levels of an internal housekeeping gene, cyclophilin, or GAPDH, in the same sample, and this ratio of target gene expression to housekeeping gene expression was calculated in each rat using the standard delta-delta $C_{t}$ method. The ANOVA was then run on this ratio calculated for each subject, with the effect of ethanol on target gene expression determined by comparing the average of the ratio in the experimental groups with the control groups, as well as the control groups with each other. These average ratio scores (see Figs. 2, 4, 6) are represented in these figures as "mRNA fold change" relative to the control group.

\section{Single- and double-labeling immunofluorescence}

histochemistry (IF)

IF was used, as previously described (Chang et al., 2013, 2015), to characterize the distribution pattern and quantify in adolescent offspring the cell density of MCH-, CCR2-, CCL2-, NeuN-immunoreactive cells in the $\mathrm{LH}$, the precise area outlined in the photomicrograph illustrating $\mathrm{MCH}$ neurons (Fig. 1). Briefly, female rats at P35 and male rats at P40 were perfused intracardially with $0.9 \%$ normal saline followed by $4 \%$ PFA in $\mathrm{PB}$, and their brains were removed and postfixed for $4 \mathrm{~h}$ in the same fixative at $4^{\circ} \mathrm{C}$, cryoprotected in $25 \%$ sucrose at $4^{\circ} \mathrm{C}$ for $72-96 \mathrm{~h}$, and then frozen and stored at $-80^{\circ} \mathrm{C}$. They were cut at $30 \mu \mathrm{m}$ with a cryostat, and free-floating coronal sections were processed with primary antibodies, and their corresponding secondary antibody, as shown in Table 1. Sections were viewed, and fluorescence images were captured using a fluorescence microscope (Carl Zeiss) with MetaVue software. For quantitation, the fluorescence image of the entire LH as shown in Figure 1 was captured using $10 \times$ objective and outlined. The density of immunofluorescent cells in this area, in 8-12 images collected for each animal at the anterior-posterior level of bregma -2.76 to $-3.36 \mathrm{~mm}$ (Paxinos and Watson, 2005), was quantified with Image-Pro Plus software (version 4.5; Media Cybernetics), as previously described (Chang et al., 2013, 2015). Only intact cells with an area of $100-200 \mu \mathrm{m}^{2}$ were counted, and the population density was used to determine the cell density reported as cells $/ \mu \mathrm{m}^{2}$.

Double-labeling IF was used to examine in the LH the coexistence of CCR2 with $\mathrm{MCH}$, of CCL2 with NeuN, CCR2 and MCH, and of CCL2 or CCR2 with GFAP and Iba-1. It was performed using a combination of 
Table 1. Antibodies used for single-labeling immunofluorescence histochemistry

\begin{tabular}{llllll}
\hline Primary antibody & Concentration & Vendor & Secondary antibody & Concentration & Vendor \\
\hline Mouse anti-NeuN & $1: 50$ & Catalog \#MAB377, EMD Millipore & Cy3-donkey anti-mouse IgG & $1: 100$ & Jackson ImmunoResearch Laboratories \\
Mouse anti-GFAP & $1: 50$ & Catalog \#MAB3402, EMD Millipore & Cy3-donkey anti-mouse IgG & $1: 100$ & Jackson ImmunoResearch Laboratories \\
Rabbit anti-Iba-1 & $1: 100$ & Catalog \#019-19741, Wako Chemicals & Cy3-donkey anti-rabbit IgG & $1: 100$ & Jackson ImmunoResearch Laboratories \\
Rabbit anti-MCH & $1: 200$ & Catalog \#H-070-47, Phoenix Pharmaceuticals & FITC-donkey anti-rabbit IgG & $1: 50$ & Jackson ImmunoResearch Laboratories \\
Goat anti-CCR2 & $1: 50$ & Catalog \#sc-6228, Santa Cruz Biotechnology & Cy3-donkey anti-goat IgG & $1: 100$ & Jackson ImmunoResearch Laboratories \\
Goat anti-CCL2 & $1: 100$ & Catalog \#sc-1785, Santa Cruz Biotechnology & FITC-donkey anti-goat IgG & $1: 50$ & Jackson ImmunoResearch Laboratories \\
\hline
\end{tabular}

Table 2. Antibodies used for double-labeling immunofluorescence histochemistry

\begin{tabular}{|c|c|c|c|c|c|c|}
\hline Combination & Primary antibody & Concentration & Vendor & Secondary antibody & Concentration & Vendor \\
\hline \multirow[t]{2}{*}{$\mathrm{CCL} 2+\mathrm{GFAP}$} & Goat anti-CCL2 & 1:100 & Catalog \#sc-1785, Santa Cruz Biotechnology & $\begin{array}{l}\text { Bio-horse anti-goat lgG }+ \\
\text { TSA fluorescein }\end{array}$ & 1:100 & Vector \\
\hline & Mouse anti-GFAP & 1:50 & Catalog \#MAB3402, EMD Millipore & Cy3-donkey anti-mouse IgG & 1:100 & Jackson ImmunoResearch Laboratories \\
\hline $\mathrm{CCL} 2+\mathrm{Iba}-1$ & Rabbit anti-lba-1 & 1:100 & Catalog \#019-19741, Wako Chemicals & Cy3-donkey anti-rabbit lgG & 1:100 & Jackson ImmunoResearch Laboratories \\
\hline CCR2 + GFAP & Goat anti-CCR2 & 1:100 & Catalog \#sc-6228, Santa Cruz Biotechnology & FITC-donkey anti-goat lgG & 1:100 & Jackson ImmunoResearch Laboratories \\
\hline CCR2 + lba-1 & Rabbit anti-lba-1 & 1:100 & Catalog \#019-19741, Wako Chemicals & Cy3-donkey anti-rabbit lgG & 1:100 & Jackson ImmunoResearch Laboratories \\
\hline \multirow[t]{2}{*}{$\mathrm{CCR} 2+\mathrm{MCH}$} & Goat anti-CCR2 & 1:50 & Catalog \#sc-6228, Santa Cruz Biotechnology & Cy3-donkey anti-goat lgG & 1:100 & Jackson ImmunoResearch Laboratories \\
\hline & Rabbit anti-MCH & 1:200 & Catalog \#H-070-47, Phoenix Pharmaceuticals & FITC-donkey anti-rabbit lgG & 1:50 & Jackson ImmunoResearch Laboratories \\
\hline \multirow[t]{2}{*}{$\mathrm{CCL} 2+\mathrm{NeuN}$} & Goat anti-CCL2 & 1:100 & Catalog \#sc-1785, Santa Cruz Biotechnology & $\begin{array}{l}\text { Bio-horse anti-goat } \lg G+ \\
\text { TSA fluorescein }\end{array}$ & 1:100 & Vector \\
\hline & Mouse anti-NeuN & 1:50 & Catalog \#MAB377, EMD Millipore & Cy3-donkey anti-mouse lgG & $1: 100$ & Jackson ImmunoResearch Laboratories \\
\hline $\mathrm{CCL} 2+\mathrm{MCH}$ & Rabbit anti-MCH & $1: 200$ & Catalog \#H-070-47, Phoenix Pharmaceuticals & Cy3-donkey anti-rabbit lgG & $1: 100$ & Jackson ImmunoResearch Laboratories \\
\hline
\end{tabular}

primary antibodies and their corresponding secondary antibodies, as listed in Table 2, based on our previous procedures (Chang et al., 2013, 2015), with the following two modifications for: (1) double-labeling of CCL2 with NeuN, MCH, GFAP, or Iba-1: after incubation in the primary antibody, sections were rinsed in PBS, $6 \times 10 \mathrm{~min}$, then incubated for 90 min in a combination of biotin-conjugated horse anti-goat IgG for CCL2 with Cy3-conjugated donkey anti-mouse IgG for NeuN and GFAP or of biotin-conjugated horse anti-goat IgG for CCL2 with Cy3-conjugated donkey anti-rabbit IgG for MCH and Iba-1, and this was followed by 30 min incubation in streptavidin-HRP (1:100 Perkin Elmer) and 5 min incubation in fluorescein tyramide (1:50, Perkin Elmer), to amplify CCL2 immunolabeling, with sections rinsed in PBS, $3 \times 10$ min, between each step; and (2) double-labeling of CCL2 with CCR2: using these same procedures, sections were incubated in goat anti-CCL2 antibody in combination with a mouse anti-CCR2 antibody.

For analysis of the double-labeled CCR2 ${ }^{+}$cells with $\mathrm{MCH}$ or doublelabeled CCL2 ${ }^{+}$cells with $\mathrm{NeuN}, \mathrm{CCR} 2$, or $\mathrm{MCH}$, the images were captured by an LSM 880 confocal microscope (Carl Zeiss) with $20 \times$ objective, and the double-labeled cells were further confirmed by $z$ stack sectioning with a $40 \times$ oil-immersion lens, with the $z$ stacks $30 \mu \mathrm{m}$ thick and step size of $0.44-0.50 \mu \mathrm{m}$ for optimal stack collection and analysis. Double-labeled cells were counted in $20 \times$ images and reported as percentage of total single-labeled cells. Cells with an area of $100-200 \mu \mathrm{m}^{2}$ at $20 \times$ or $200-400 \mu \mathrm{m}^{2}$ at $40 \times$ were defined as small cells, whereas cells with an area of $>200 \mu \mathrm{m}^{2}$ at $20 \times$ or $600-800 \mu \mathrm{m}^{2}$ at $40 \times$ were defined as large cells. In all analyses, the cells were counted only on one plane in each section, and only intact cells of a designated size were counted, thus eliminating any objects that were part of a cell or any small cells that might be edges of the larger cells. Distance between the small and large cells was measured and, in some cases, ranged from 10 to $30 \mu \mathrm{m}$ when the cells were particularly close but in other cases was up to $200 \mu \mathrm{m}$. To confirm that the small CCL2 cells were not debris or edges of the larger cells, DAPI was used to stain the nucleus, confocal $z$ stack sectioning (30 $\mu \mathrm{m}$ thick and step size of $1.02 \mu \mathrm{m})$ of the double-labeling DAPI and CCL2 at 20× was collected, 3D images were reconstituted, and DAPI/ CCL2 colabeled cells were analyzed using Imaris image analysis software (version 9.12, 2018). This analysis demonstrated that almost all of the small CCL2 cells were labeled with DAPI, indicating that they were independent intact cells.

\section{Ethanol intake and blood ethanol concentration}

The female (P35) and male (P40) adolescent offspring, from dams exposed daily (E10-E15) to either ethanol $(2 \mathrm{~g} / \mathrm{kg} / \mathrm{d})$ or its control solution or to either CCL2 (4 and $8 \mu \mathrm{g} / \mathrm{kg} / \mathrm{d}$ ) versus its vehicle control, were trained to voluntarily drink ethanol for 3 weeks using the $20 \%$ intermittent-access paradigm, as previously described (Simms et al., 2008; Barson et al., 2015; Chang et al., 2015). Their $24 \mathrm{~h}$ intake of ethanol, water, and chow was recorded 3 times weekly and averaged across the 3 week period. On the last day of the testing period, blood was collected from the tail vein $30 \mathrm{~min}$ after the daily ethanol presentation, and measurements were taken of BEC using a GM7 Alcohol Analyzer (Analox).

\section{Novel open field test}

Testing was conducted in a sound- and light-attenuated room ( $<5$ lux) starting $1 \mathrm{~h}$ into the dark cycle. Female (P35) and male (P40) rats were tested in a novel open field for measurements of anxiety and locomotor activity, as previously described (Barson et al., 2015; Pandey et al., 2017). Each rat was placed in a novel $43.2 \mathrm{~cm} \times 43.2 \mathrm{~cm}$ activity test chamber (Med Associates) and tested for $5 \mathrm{~min}$ to measure freezing time and time spent in the center, reflecting anxiety behavior (Ramos et al., 2003; Kanari et al., 2005), and to measure ambulatory distance and ambulatory counts (number of infrared beam breaks), indicating locomotor activity (Barson et al., 2015; Pandey et al., 2017).

\section{Experimental design and statistical analysis}

Maternal ethanol effect on CCR2 and MCH mRNA in LH of adolescent offspring. To determine the effect of maternal ethanol exposure on 
mRNA levels of CCR2 and MCH in adolescent offspring, the dams received daily intraoral infusions of either ethanol at a moderate dose for $5 \mathrm{~d}(2 \mathrm{~g} / \mathrm{kg} / \mathrm{d}, \mathrm{E} 10-\mathrm{E} 15)$ or an isocaloric maltose-dextrin control solution (control) or were an untreated control (untreated), and the gene expression of CCR2 and $\mathrm{MCH}$ in the LH of the pubertal female (P35) and male (P40) offspring ( $n=9 /$ group/sex) was measured using qRT-PCR. While our prior studies (Chang et al., 2012, 2015) showing maternal ethanol to similarly stimulate gene expression in offspring at all ages (from P15 to P90) suggest that the 5 day difference in age between the females and males would not be a major factor in determining sex differences, we tested and confirmed this, in a preliminary experiment examining in female and male offspring ( $n=5$ /group) at the same age (P40), the effect of prenatal ethanol exposure $(2 \mathrm{~g} / \mathrm{kg} / \mathrm{d})$ versus control isocaloric maltose-dextrin solution on gene expression (via qRT-PCR) of $\mathrm{MCH}$ mRNA in the LH. Data analysis using a two-way ANOVA revealed a significant main effect of maternal ethanol treatment $\left(F_{(1,16)}=39.74\right.$, $p=0.000)$ with no main effect of $\operatorname{sex}\left(F_{(1,16)}=0.882, p=0.362\right)$ and a significant interaction between treatment and sex $\left(F_{(1,16)}=5.51, p=\right.$ $0.032)$, and the simple main effect analyses showing no difference ( $p=$ $0.334)$ between female $(0.228 \pm 0.019)$ and male $(0.259 \pm 0.019)$ controls revealed significantly higher $(p=0.034) \mathrm{MCH}$ mRNA levels in ethanol-exposed females $(0.417 \pm 0.021)$ compared with males $(0.345 \pm$ 0.027 ), with direct comparisons between females and males (via paired $t$ test) showing the ethanol-induced increase in $\mathrm{MCH}$ gene expression to be significantly greater in females $\left(t_{(8)}=2.81, p=0.023\right)$.

Maternal ethanol effect on $\mathrm{CCR} 2^{+}$and $\mathrm{MCH}^{+}$neurons in LH of adolescent offspring. The density of single-labeled CCR $2^{+}$and $\mathrm{MCH}^{+}$neurons, both heavily concentrated in the LH, and their double-labeling were examined using IF in female (P35) and male (P40) adolescent offspring ( $n=7 /$ group/sex) from dams that received daily intraoral infusions of ethanol (2 g/kg/d, E10-E15) or the isocaloric maltose-dextrin control solution (control) or that were an untreated control (untreated).

Maternal ethanol effect on CCL2 MRNA and cell density in LH of adolescent offspring. To determine the effect of maternal ethanol administration on CCL2 in the LH of adolescent offspring as well as peripheral CCL2 levels in the dam, three sets of pregnant rats received daily intraoral infusions of either ethanol ( $2 \mathrm{~g} / \mathrm{kg} / \mathrm{d}, \mathrm{E} 10-\mathrm{E} 15)$ or an isocaloric maltosedextrin control solution (control). In Set 1, we measured in the dams ( $n=9$ /group) their levels of CCL2 in blood collected from tail vein at E15 and amniotic fluid collected from the female and male embryos at E19, using a mouse CCL2 ELISA kit (R\&D Systems) according to the manufacturer's instructions, with protein levels of CCL2 calculated relative to the standard curve of the standard samples. In Set 2, brains of the female (P35) and male (P40) adolescent offspring ( $n=9 /$ group/sex) were examined using qRT-PCR for measurements of mRNA levels of CCL2 in the LH. In Set 3, brains of the female and male adolescent offspring $(n=$ 8 /group/sex) were examined using IF for measurements of CCL2 ${ }^{+}$cell density in the LH.

Maternal ethanol effect on ethanol intake and anxiety in adolescent offspring. Two sets of dams were used to examine the effect of maternal ethanol administration on the behavior of adolescent offspring. In Set 1, using a two-bottle choice paradigm under an intermittent access schedule, we measured ethanol intake as well as water and food intake and BEC in both female (P35) and male (P40) adolescent offspring ( $n=10 /$ group/ sex) from dams that received daily intraoral infusions of either ethanol (2 $\mathrm{g} / \mathrm{kg} / \mathrm{d}, \mathrm{E} 10-\mathrm{E} 15)$ or an isocaloric control solution (control). In Set 2, the female (P35) and male (P40) offspring ( $n=7 /$ group/sex) from dams given daily intraoral infusions of either ethanol $(2 \mathrm{~g} / \mathrm{kg} / \mathrm{d}$, E10-E15) or an isocaloric control solution (control) were tested in a novel open field for measurements of anxiety and locomotor activity.

Maternal CCL2 effect on CCL2/CCR2 and MCH expression and cell density in LH of adolescent offspring. To determine the effect of maternal CCL2 administration on CCL2, CCR2 and MCH expression and cell density in the adolescent offspring, we gave in two sets of dams daily injections (E10-E15) of CCL2 at one of two doses ( 4 or $8 \mu \mathrm{g} / \mathrm{kg} / \mathrm{d}$, s.c.) compared with vehicle control (sterile water). In Set 1, we measured the dam's daily food and water intake, litter size, and average body weight of pups at birth and used qRT-PCR to measure the mRNA levels of CCR2 and $\mathrm{MCH}$ as well as CCL2 in the LH of female (P35) and male (P40) adolescent offspring ( $n=9 /$ group/sex). In Set 2 , we examined in female adolescent offspring only ( $n=7 /$ group) the effect of CCL2 (4 or $8 \mu \mathrm{g} /$ $\mathrm{kg} / \mathrm{d}$, s.c., E10-E15) or its vehicle control (control) or no treatment (untreated) on the $\mathrm{CCR}_{2}{ }^{+}$and $\mathrm{MCH}^{+}$neurons using single- and double-labeling IF. With the tissue from the lower CCL2 dose $(4 \mu \mathrm{g} /$ $\mathrm{kg} / \mathrm{d}$ ) lost in this experiment, only the data from the $8 \mu \mathrm{g} / \mathrm{kg} / \mathrm{d}$ CCL2 dose compared with the control groups are described in the results.

Maternal CCL2 effect on ethanol drinking and anxiety in adolescent offspring. To determine the effect of maternal CCL2 administration on behavior in adolescent offspring, two sets of dams were given daily injections of CCL2 (4 or $8 \mu \mathrm{g} / \mathrm{kg} / \mathrm{d}$, s.c., E10-E15) versus its vehicle control (sterile water), and measurements were taken in both female (P35) and male (P40) adolescent offspring of their ethanol intake, anxiety-like behavior, and locomotor activity. In Set $1(n=10$ /group/sex $)$, using a two-bottle choice paradigm under an intermittent access schedule, we measured ethanol intake and BEC along with water and food intake. In Set $2(n=7 /$ group/sex), we measured both anxiety and locomotor activity in a novel open field.

Relationship of CCL2 neurons in LH to CCR2 and MCH neurons when stimulated by maternal ethanol exposure. To further investigate the endogenous CCL2/CCR2 system in the LH as it relates to MCH neurons, we examined female adolescent offspring ( $n=7 /$ group/set) from three sets of dams that received intraoral infusions of ethanol ( $2 \mathrm{~g} / \mathrm{kg} / \mathrm{d}, \mathrm{E} 10-\mathrm{E} 15)$ or the isocaloric control solution (control). In Set 1, brains of the offspring were examined using single-labeling IF to test the effect of ethanol on the density of cells single-labeling CCL2, as well as the astrocyte marker GFAP and the microglia marker Iba-1. In Set 2, brains of the offspring were examined using double-labeling IF and confocal microscopy to further characterize the CCL2 ${ }^{+}$cells and their colocalization with the neuronal marker NeuN, as well as GFAP or Iba-1. In Set 3, brains of the offspring were examined for the effect of maternal ethanol on the density of CCL2 ${ }^{+}$neurons that double-labeled CCR2 or MCH in the LH.

Effect of CCR2 receptor antagonism on maternal ethanol-induced changes in CCR2/MCH neurons and behavior. With strong evidence that maternal ethanol has a strong stimulatory effect in offspring brain on CCR2 and CCL2 as well as behavior, we next wanted to test the involvement of CCR2 in mediating the maternal ethanol-induced effects. We tested three sets of pregnant rats with administration of the CCR2 receptor antagonist, INCB3344, from E10-E15, during the same time as ethanol administration. Administration of the CCR2 antagonist together with ethanol allowed us to directly test whether the CCR2 receptor during this developmental period was required for the stimulatory effects of ethanol on the brain and behavior. With no prior studies of this CCR2 antagonist during pregnancy, we selected a dose $(1 \mathrm{mg} / \mathrm{kg})$ used in prior studies of inflammation and pain in rats (Dansereau et al., 2008; Van Steenwinckel et al., 2011). In Set 1 ( $n=4$ /group), the dams were injected daily with INCB3344 (1 mg/kg/d, s.c., E10-E15) or its vehicle $(10 \%$ DMSO) to test whether it had any adverse effects on their food and water intake and body weight and also on the pups' body weight. The results of these measurements revealed no changes in the dam's food intake $\left(t_{(6)}=\right.$ $1.06, p=0.465,72 \pm 9 \mathrm{vs} 65 \pm 8 \mathrm{kcal} / \mathrm{d}$, respectively), water intake $\left(t_{(6)}=1.23, p=0.618,20 \pm 5 \mathrm{vs} 19 \pm 3 \mathrm{ml} / \mathrm{d}\right.$, respectively), and body weight $\left(t_{(6)}=1.98, p=0.703,451 \pm 4.9 \mathrm{vs} 446 \pm 4.41 \mathrm{~g}\right)$, and in the pup's body weight at birth $\left(t_{(6)}=1.06, p=0.465,8.2 \pm 2.1\right.$ vs $\left.7.5 \pm 1.6 \mathrm{~g}\right)$, with no spontaneous abortions observed. In Sets 2 and 3, we used this dose to test female adolescent offspring (P35) from pregnant rats given intraoral administration of ethanol (2 $\mathrm{g} / \mathrm{kg} / \mathrm{d}, \mathrm{E} 10-\mathrm{E} 15)$ or its isocaloric control and then injected $30 \mathrm{~min}$ later with either INCB3344 (1 mg/kg/d, s.c.) or its vehicle, producing the following 4 groups/set: isocaloric control + vehicle (control), ethanol + vehicle (ethanol), ethanol + INCB3344, and control + INCB3344. The offspring from Set $2(n=7$ /group) were killed and their brains analyzed using IF to measure the density of CCR2 ${ }^{+}$and $\mathrm{MCH}^{+}$single- and double-labeled neurons, whereas the offspring from Set 3 ( $n=10$ /group) were trained to drink ethanol, and their intake of ethanol and water was measured.

\section{Statistical analysis}

All data are presented as mean \pm SEM and were analyzed using SPSS (version 24, IBM). All graphs were prepared using the Prism software 
(version 6, GraphPad). Data in experiments using female and male offspring were analyzed using a two-way ANOVA, which tested withinsubject main effects of maternal treatment, such as ethanol or CCL2, and their respective controls, between-subject main effects of sex, and the interactions between maternal treatment and sex. A significant interaction was interpreted using simple main effect analyses to test the differences between females and males as well as differences within each sex. A paired $t$ test was performed to directly compare the effect of maternal treatment versus control within each sex. In experiments that tested females only, a one-way ANOVA was used to evaluate the effect of maternal CCL2 injection on CCR $2^{+}$and $\mathrm{MCH}^{+}$single- and double-labeled neurons in the LH and the effect of maternal CCR2 antagonist administration on CCR $2{ }^{+}$and $\mathrm{MCH}^{+}$neurons and on ethanol intake, followed by LSD post hoc tests. Paired $t$ tests were used to analyze the effects of maternal ethanol versus control on $\mathrm{GFAP}^{+}$and Iba- ${ }^{+}{ }^{+}$cells, on CCL2 ${ }^{+}$/ $\mathrm{NeuN}^{+}$small and large double-labeled neurons, and on large CCL2 ${ }^{+}$/ $\mathrm{CCR} 2{ }^{+}$and $\mathrm{CCL} 2{ }^{+} / \mathrm{MCH}^{+}$double-labeled neurons.

\section{Results}

Maternal ethanol administration stimulates expression of CCR2 and MCH in female and male adolescent offspring

Our first step was to determine whether maternal intraoral ethanol administration alters the gene expression of CCR2 and $\mathrm{MCH}$ in the $\mathrm{LH}$ of female and male offspring at the start of adolescence and whether these effects differ between the sexes. Analysis via a two-way ANOVA revealed a significant main effect of maternal treatment on mRNA levels of both CCR2 $\left(F_{(2,48)}=32.60, p=\right.$ $0.000)$ and $\mathrm{MCH}\left(F_{(2,48)}=39.87, p=0.000\right)$, which reflects a significant increase in their expression in both females and males after in utero ethanol exposure compared with control groups (Fig. 2). Interestingly, we also observed, for the first time, a significant effect of sex on CCR2 $\left(F_{(1,48)}=8.88, p=0.005\right)$ but not $\mathrm{MCH}\left(F_{(1,48)}=1.31, p=0.259\right)$ and a significant interaction between sex and maternal treatment for both CCR2 $\left(F_{(2,48)}=\right.$ $8.25, p=0.001)$ and $\mathrm{MCH}\left(F_{(2,48)}=3.95, p=0.026\right)$. Simple main effect analyses of the data from the two control groups showed no differences between the females and males in their mRNA levels of CCR2 $(p=0.88$ for control and $p=0.981$ for untreated $)$ and $\mathrm{MCH}(p=0.51$ for control and $p=0.772$ for untreated) and no differences between the control and untreated groups for females $(p=0.820)$ or males $(p=0.880)$, indicating that the intraoral infusion itself had little effect on gene expression. After in utero ethanol exposure, however, these analyses revealed clear differences between the female and male offspring, with the females having significantly higher levels than the males of both CCR2 $(p=0.001)$ and MCH $(p=0.005)$ mRNA in the LH (Fig. 2). Direct comparisons between the females and males (via paired $t$ test) of their ethanol-induced increase in gene expression showed this effect to be significantly greater in the females, with measurements of CCR2 mRNA compared with the control $\left(t_{(16)}=3.05, p=0.010\right)$ and untreated $\left(t_{(16)}=3.06, p=\right.$ $0.010)$ groups and of MCH mRNA compared with the control $\left(t_{(16)}=2.06, p=0.049\right)$ and untreated $\left(t_{(16)}=3.07, p=0.008\right)$ groups. Thus, while confirming our prior study in male weanling offspring (Chang et al., 2015), these findings additionally show that the stimulatory effect of in utero ethanol exposure on CCR2 and $\mathrm{MCH}$ expression persists into adolescence and is sexually dimorphic, considerably stronger in females as noted in particular by the unusually large increase in CCR2 mRNA in the LH.

Maternal ethanol administration increases the density of $\mathrm{CCR}^{+}{ }^{+}$and $\mathrm{MCH}^{+}$neurons in female and male offspring This experiment next examined in female and male adolescent offspring the effects of maternal ethanol administration on both

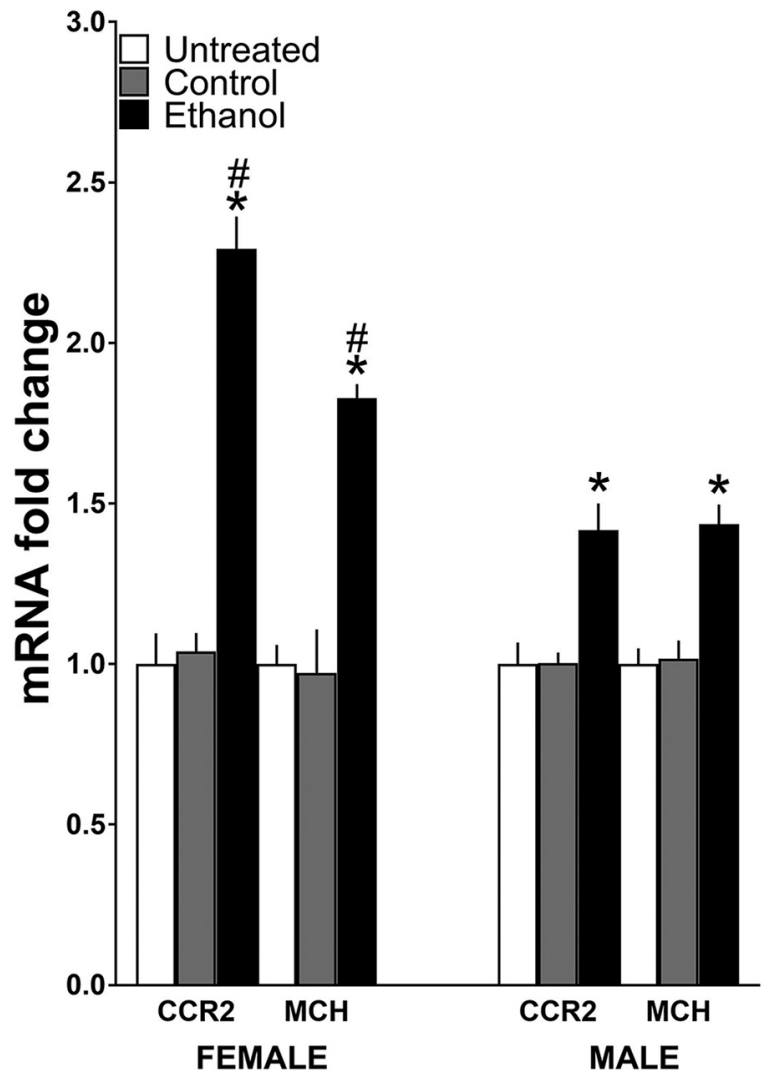

Figure 2. Maternal administration of ethanol ( $2 \mathrm{~g} / \mathrm{kg} / \mathrm{d}, \mathrm{E} 10-\mathrm{E} 15)$ compared with isocaloric control solution and untreated control groups affects mRNA expression of CCR2 and MCH in the LH of adolescent offspring ( $n=9 /$ group/sex), measured using qRT-PCR and represented in the figure as mRNA fold change compared with the untreated control group (with average ratio scores given in parentheses). Ethanol compared with control groups ( $n=9 /$ group/sex) significantly increased in female offspring mRNA levels of MCH (untreated $=0.203 \pm 0.012$, control $=0.198 \pm 0.027$, ethanol $=0.372 \pm 0.016$ ) and CCR2 (untreated $=0.150 \pm 0.0143$, control $=0.157 \pm 0.009$, and ethanol $=0.344 \pm 0.034$ ) and in male offspring mRNA levels of $M C H$ (untreated $=0.210 \pm 0.010$, control $=0.214 \pm 0.012$, and ethanol $=0.302 \pm 0.018$ ) and CCR2 (untreated $=0.151 \pm 0.010$, control $=0.155 \pm 0.005$, and ethanol $=0.215 \pm$ 0.018 ), with the effect significantly greater in females, which exhibited a particularly large increase in CCR2. Data are mean \pm SEM. ${ }^{*} p<0.05$ versus control groups. ${ }^{\#} p<0.05$ versus male groups.

$\mathrm{CCR}^{+}{ }^{+}$cells shown to be neurons (Chang et al., 2015) and $\mathrm{MCH}^{+}$neurons in the $\mathrm{LH}$ and also the colocalization of CCR2 with $\mathrm{MCH}$. Analysis via a two-way ANOVA of the single-labeled neurons revealed a significant main effect of maternal treatment on the density of both CCR2 ${ }^{+}\left(F_{(2,36)}=30.91, p=0.000\right)$ and $\mathrm{MCH}^{+}\left(F_{(1,36)}=38.22, p=0.000\right)$ neurons (Fig. 3A), reflecting a significant increase in both females and males after in utero ethanol exposure compared with control groups, as illustrated in the photomicrographs (Fig. 3B). As with gene expression, this analysis also revealed a significant main effect of sex on the density of CCR2 ${ }^{+}\left(F_{(1,36)}=9.59, p=0.004\right)$ and $\mathrm{MCH}^{+}\left(F_{(1,36)}=\right.$ 7.27, $p=0.110)$ neurons and a significant interaction between sex and maternal treatment for CCR $\left.{ }^{+}{ }_{\left(F_{(2,36)}\right.}=5.67, p=0.007\right)$ and $\mathrm{MCH}^{+}\left(F_{(2,36)}=9.04, p=0.001\right)$ neurons. Simple main effect analyses of the data from the two control groups revealed no differences between the females and males in their density of $\mathrm{CCR}^{+}(p=0.347$ for control and $p=0.095$ for untreated $)$ and $\mathrm{MCH}^{+}(p=0.792$ for control and $p=0.737$ for untreated $)$ neurons and also between the control and untreated groups for females $(p=0.700)$ and males $(p=0.535)$, showing again that the intraoral infusion itself had little effect on these LH neurons. 

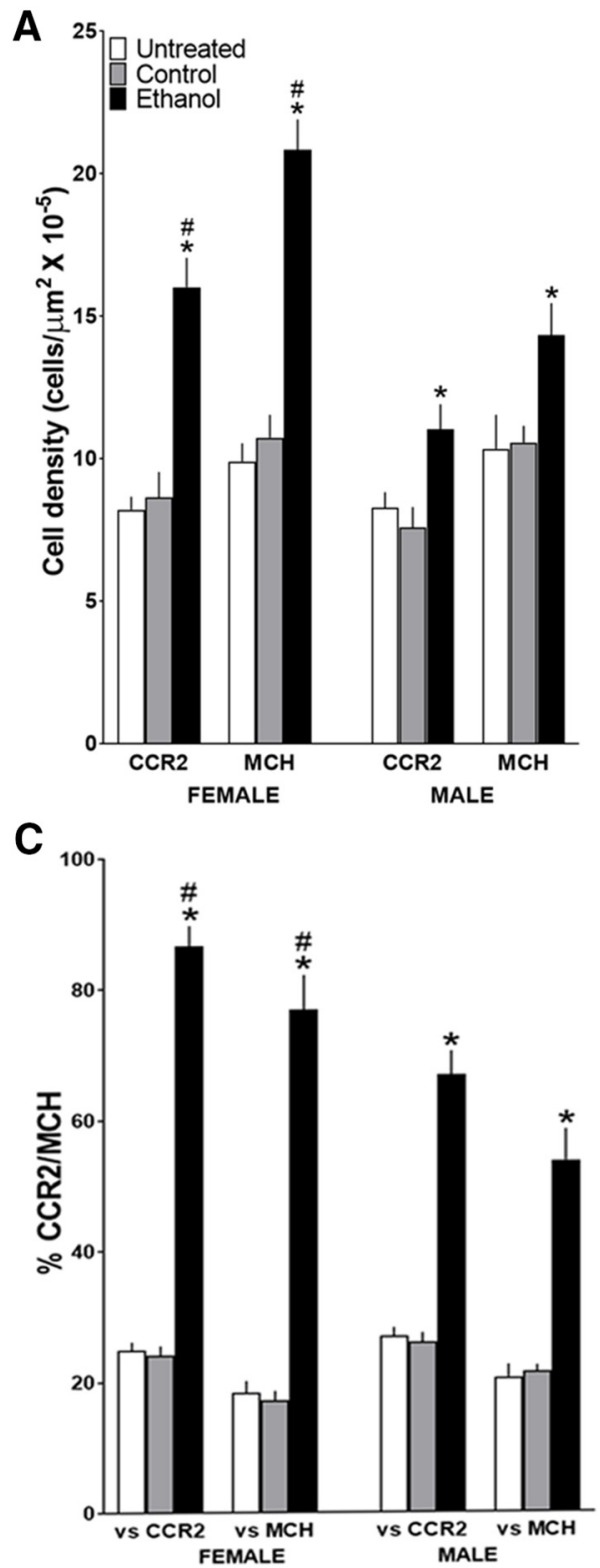

B
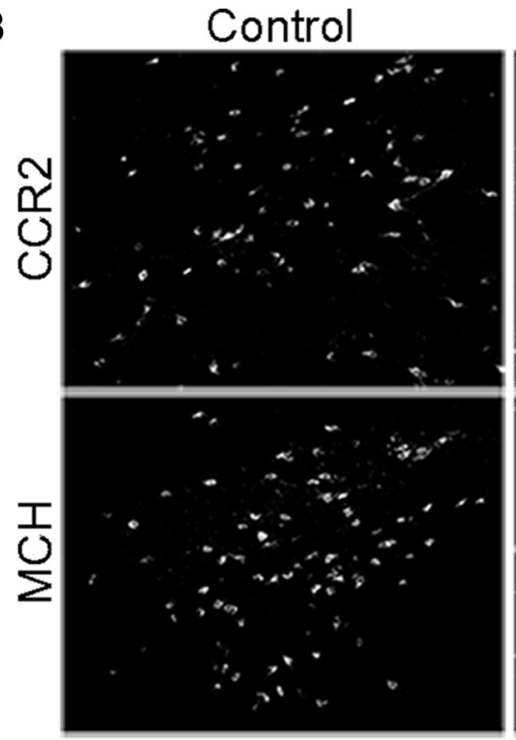

D

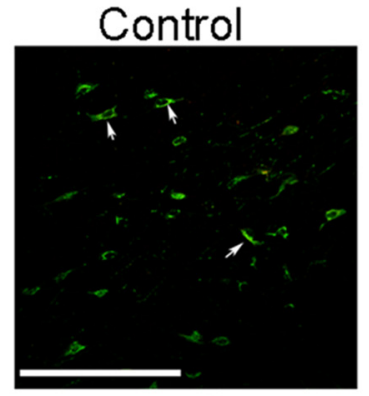

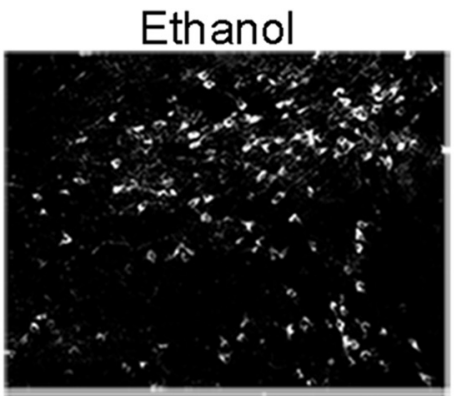

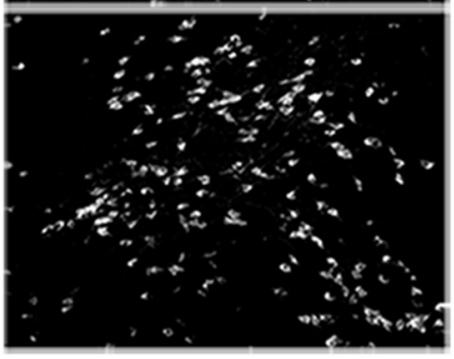

Ethanol
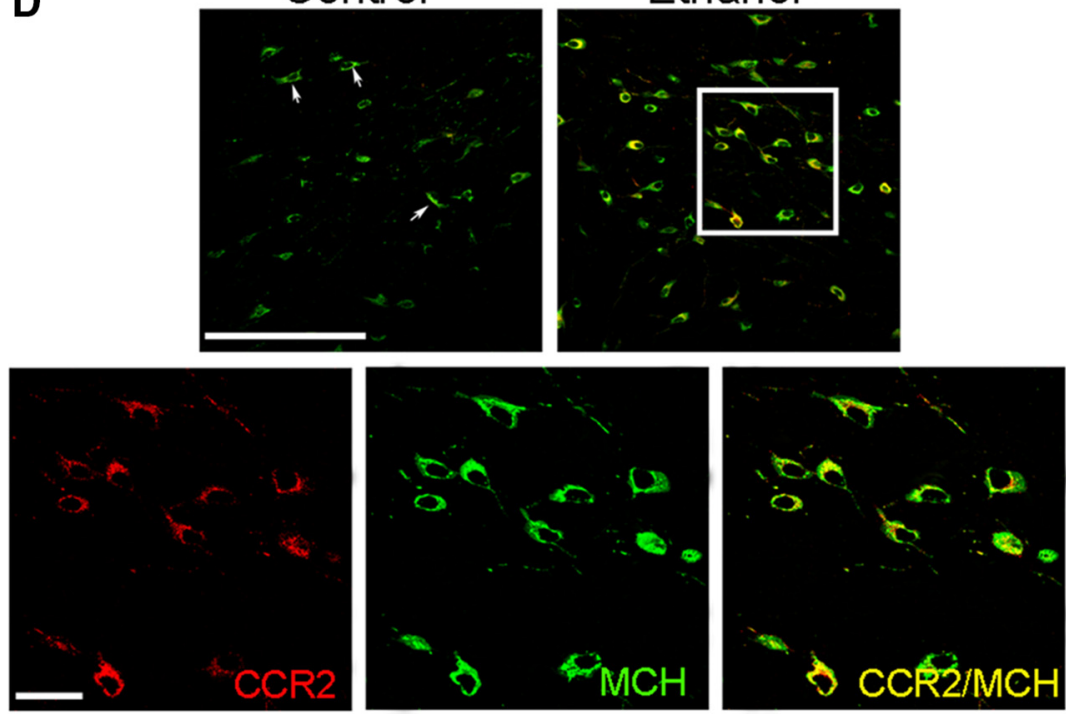

Figure 3. Maternal ethanol administration (2 $\mathrm{g} / \mathrm{kg} / \mathrm{d}$, E10-E15) compared with isocaloric control and untreated control groups affects $\mathrm{CCR2}^{+}$and MCH ${ }^{+}$neurons in the LH of adolescent offspring ( $n=7 / \mathrm{group} / \mathrm{sex}$ ), as measured using IF. $A$, Ethanol compared with control groups significantly increased the density of $\mathrm{CCR2}{ }^{+}$and $\mathrm{MCH}{ }^{+}$single-labeled neurons in both female and male offspring, with the effects in females significantly larger. $\boldsymbol{B}$, This effect in female offspring is illustrated in representative immunostaining images of $\mathrm{CCR2}^{+}$and $\mathrm{MCH}^{+}$single-labeled neurons. $\boldsymbol{C}$, Ethanol increased the density of $\mathrm{CCR}^{+} / \mathrm{MCH}^{+}$double-labeled neurons in both female and male offspring, again with this effect significantly stronger in females. $\boldsymbol{D}$, This effect of ethanol on double-labeled neurons is illustrated in the confocal images from female offspring showing $\mathrm{CCR2}^{+}$(red) and $\mathrm{MCH}^{+}$(green) single-labeled neurons and $\mathrm{CCR2}^{+} / \mathrm{MCH}^{+}$(yellow) double-labeled neurons in the LH. Top, A few $\mathrm{CCR}^{+} / \mathrm{MCH}^{+}$neurons (arrows) in control offspring and many in ethanol-exposed offspring, with those in the white square illustrated (bottom) at higher magnification for $\mathrm{CCR2}^{+}$and $\mathrm{MCH}^{+}$single-labeled and $\mathrm{CCR2}{ }^{+} / \mathrm{MCH}^{+}$double-labeled neurons. Scale bars, $200 \mu \mathrm{m}$. Data are mean \pm SEM. ${ }^{*} p<0.05$ versus control group. ${ }^{\#} p<0.05$ versus male groups.

These analyses, however, revealed clear differences between the female and male offspring exposed in utero to ethanol, with the females having a significantly higher density $(p=0.000)$ of both the CCR ${ }^{+}$and $\mathrm{MCH}^{+}$neurons (Fig. $3 A$ ). Direct comparisons between females and males (via paired $t$ test) of ethanol's stimulatory effect on their density showed this effect to be significantly greater in the females, with measurements of both CCR2 ${ }^{+}$neurons compared with the control $\left(t_{(12)}=2.51, p=0.028\right)$ and untreated $\left(t_{(12)}=3.64, p=0.003\right)$ groups and $\mathrm{MCH}^{+}$neurons compared with the control $\left(t_{(12)}=3.52, p=0.004\right)$ and untreated $\left(t_{(12)}=4.49, p=0.001\right)$ groups.

Analyses of the double-labeled $\mathrm{CCR} 2^{+} / \mathrm{MCH}^{+}$neurons in the LH similarly revealed a significant main effect of maternal treatment on their density relative to total single-labeled CCR2 ${ }^{+}$ $\left(F_{(2,36)}=346.79, p=0.000\right)$ and $\mathrm{MCH}^{+}\left(F_{(1,24)}=144.01, p=\right.$ 0.023 ) neurons (Fig. $3 C$ ), showing a significant increase in both females and males after in utero ethanol exposure versus control groups as illustrated in the confocal images (Fig. 3D). There was also a significant main effect of sex on the density of these doublelabeled neurons relative to total single-labeled CCR2 ${ }^{+}\left(F_{(1,36)}=\right.$ 8.48, $p=0.006)$ and $\mathrm{MCH}^{+}\left(F_{(1,36)}=4.52, p=0.041\right)$ neurons and a significant sex $\times$ maternal treatment interaction for their density relative to total CCR ${ }^{+}\left(F_{(2,36)}=15.55, p=0.001\right)$ and $\left.\mathrm{MCH}^{+}{ }_{\left(F_{(2,36)}\right.}=11.49, p=0.00\right)$ neurons. As with singlelabeled neurons, simple main effect analyses of double-labeled $\mathrm{CCR} 2{ }^{+} / \mathrm{MCH}^{+}$neurons in the two control groups revealed no 
differences between the females and males, in their density relative to total single-labeled CCR2 ${ }^{+}(p=0.638$ for control and $p=$ 0.573 for untreated $)$ and $\mathrm{MCH}^{+}(p=0.346$ for control and $p=$ 0.622 for untreated) neurons and no differences between the control and untreated groups, for females relative to CCR ${ }^{+}(p=$ $0.267)$ and $\mathrm{MCH}^{+}(p=0.309)$ neurons and for males relative to $\mathrm{CCR}^{+}(p=0.809)$ and $\mathrm{MCH}^{+}(p=0.796)$ neurons, showing the isocaloric control solution to have little effect of its own. In the ethanol-exposed offspring, in contrast, these analyses revealed sex differences, with the females compared with males having a significantly higher density of the $\mathrm{CCR} 2{ }^{+} / \mathrm{MCH}^{+}$neurons relative to both CCR ${ }^{+}(p=0.001)$ and $\mathrm{MCH}^{+}(p=0.001)$ single-labeled neurons (Fig. $3 C$ ). Direct comparisons between the females and males (via paired $t$ test) of ethanol's stimulatory effect on $\mathrm{CCR}_{2}{ }^{+} / \mathrm{MCH}^{+}$neuronal density showed this to be significantly greater in females, relative to single-labeled CCR ${ }^{+}$ neurons versus control $\left(t_{(12)}=4.59, p=0.001\right)$ and untreated $\left(t_{(12)}=3.69, p=0.003\right)$ groups and to single-labeled $\mathrm{MCH}^{+}$ neurons versus control $\left(t_{(12)}=3.57, p=0.004\right)$ and untreated $\left(t_{(12)}=3.24, p=0.007\right)$ groups. In female offspring that exhibited $\sim 100 \%$ increase in the density of both CCR2 ${ }^{+}$and $\mathrm{MCH}^{+}$ single-labeled neurons, ethanol markedly increased to $87 \%$ the percentage of $\mathrm{CCR} 2{ }^{+}$neurons that double-labeled $\mathrm{MCH}$ in the LH. Thus, in addition to their gene expression, maternal ethanol administration increases the density of CCR2 ${ }^{+}$and $\mathrm{MCH}^{+}$neurons and their double-labeling in both female and male adolescent offspring, with this effect considerably stronger in females.

\section{Maternal ethanol administration increases CCL2 mRNA and} cell density in female and male adolescent offspring

Our next goal was to test whether maternal ethanol administration also affects CCL2 in the LH, both its expression and cell density, in the female and male offspring and whether this is accompanied by changes in peripheral CCL2 levels in the pregnant rat. At the moderate dose tested ( $2 \mathrm{~g} / \mathrm{kg} / \mathrm{d}, \mathrm{E} 10-\mathrm{E} 15)$, maternal intraoral administration of ethanol compared with isocaloric control produced no change (via paired $t$ test) in CCL2 levels in the dam's serum $\left(t_{(16)}=-1.524, p=0.147,512 \pm 40 \mathrm{vs}\right.$ $426 \pm 40 \mathrm{pg} / \mathrm{ml}$ ). Also, analysis via a two-way ANOVA showed no effect of ethanol treatment on CCL2 levels in the amniotic fluid of the embryos at $\operatorname{E19}\left(F_{(1,32)}=3.935, p=0.061\right)$, and there was no effect of $\operatorname{sex}\left(F_{(1,32)}=0.61 p=0.442\right)$, with no difference in CCL2 levels detected between the ethanol and control embryos for both females $(243 \pm 20$ vs $213 \pm 18 \mathrm{pg} / \mathrm{ml})$ and males $(236 \pm 23 \mathrm{vs}$ $189 \pm 17 \mathrm{pg} / \mathrm{ml})$. This lack of change in the peripheral levels of CCL2 following a moderate dose of ethanol contrasts with the significant increase in CCL2 produced by higher ethanol doses in adult rats (Crews et al., 2015) and in offspring exposed to ethanol during the neonatal period (Drew and Kane, 2014; Kane et al., 2014).

In contrast, measurements of CCL2 in the LH of the adolescent offspring revealed marked changes and sex differences. A two-way ANOVA showed a significant main effect of maternal treatment on CCL2 mRNA expression $\left(F_{(1,32)}=41.27, p=0.000\right.$; Fig. $4 A)$ and on CCL2 ${ }^{+}$single-labeled cells $\left(F_{(1,28)}=26.29, p=\right.$ 0.000 ; Fig. $4 B)$, reflecting an increased density in both females and males after in utero ethanol exposure versus control group, as illustrated in the photomicrographs (Fig. $4 C$ ). There was also a significant main effect of sex on both CCL2 mRNA $\left(F_{(1,28)}=\right.$ 13.45, $p=0.001)$ and CCL ${ }^{+}$cell density $\left(F_{(1,28)}=9.57, p=\right.$ $0.004)$ and a significant interaction between sex and maternal treatment for both CCL2 mRNA $\left(F_{(1,28)}=13.45, p=0.001\right)$ and cell density $\left(F_{(1,28)}=26.29, p=0.001\right)$. While simple main effect
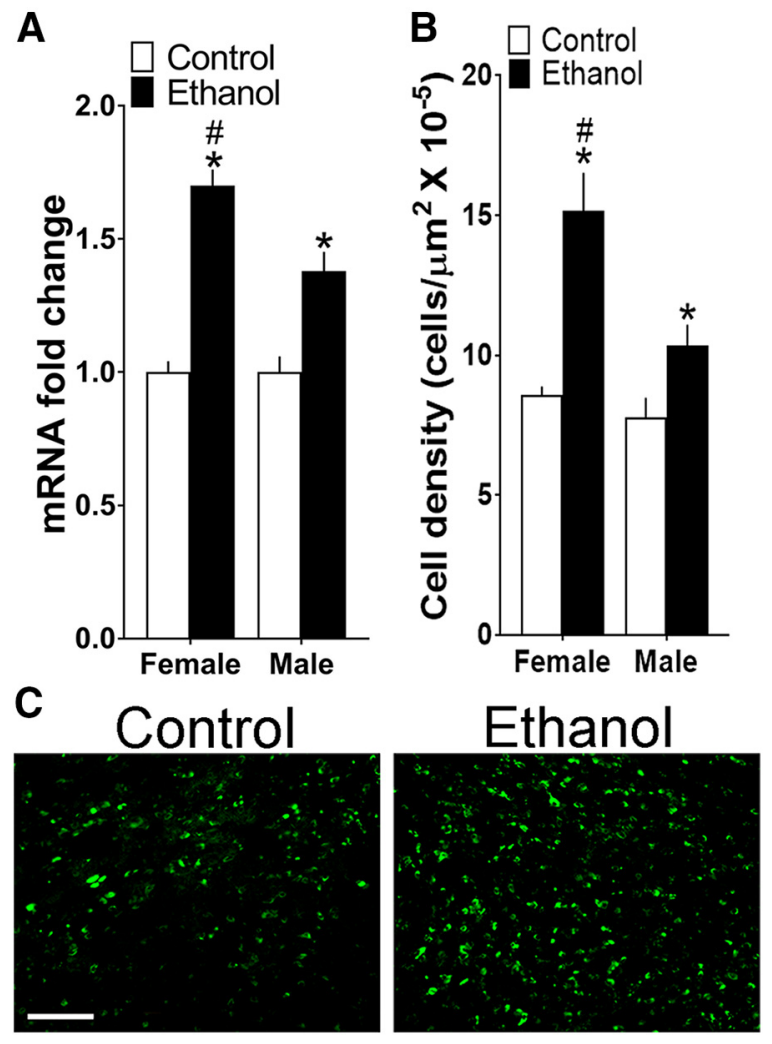

Figure 4. Maternal ethanol administration (2 $\mathrm{g} / \mathrm{kg} / \mathrm{d}$, E10-E15) compared with control solution al so affects $C C L 2$ in the $L H$ of the adolescent offspring. $A$, Ethanol increased mRNA levels of CCL2, measured using qRT-PCR and represented in the figure as mRNA fold change compared with the control group (with average ratio scores given in parentheses), in female (control = $0.249 \pm 0.015$, ethanol $=0.425 \pm 0.031$ ) and male (control $=0.220 \pm 0.013$, ethanol $=$ $0.305 \pm 0.25$ ) offspring ( $n=9 /$ group/sex), with this effect stronger in females. $\boldsymbol{B}$, Ethanol increased the density of $\mathrm{CCL}^{+}$cells measured using IF in the LH of female and male offspring ( $n=8 /$ group/sex), again with this effect greater in females. C, This effect of ethanol versus control on $\mathrm{CCL} 2{ }^{+}$cells is illustrated in the photomicrographs in female offspring. Scale bar, 200 $\mu \mathrm{m}$. Data are mean \pm SEM. ${ }^{*} p<0.05$ versus control group. ${ }^{*} p<0.05$ versus male group.

analyses under the control condition revealed no differences between female and male offspring in the measures of CCL2 mRNA $(p=0.321)$ or cell density $(p=0.550)$, these measures in ethanol-exposed offspring were significantly greater in females compared with males, for both mRNA levels $(p=0.000)$ and cell density $(p=0.001)$ in the LH (Fig. $4 A, B)$. Direct comparisons between the females and males (via paired $t$ test) of ethanol's stimulatory effects on CCL2 in the LH showed the ethanolinduced change to be significantly greater in females, again for measurements of both CCL2 mRNA $(p=0.000)$ and cell density $(p=0.023)$. Thus, while maternal ethanol administration at a moderate dose has no effect on CCL2 levels in the serum and amniotic fluid of the dam, it strongly stimulates both the expression and cell density of CCL2 in the LH of adolescent offspring, similar to its effects on CCR2, and it produces these effects in a sexually dimorphic manner, with the females more affected than males.

\section{Maternal ethanol administration stimulates ethanol intake} and anxiety in female and male adolescent offspring

With the CCL2/CCR2 and MCH systems both suggested to be positively linked to ethanol drinking and anxiety-like behaviors (see Introduction), we tested here whether the stimulatory effects of maternal ethanol on these systems in the LH are accompanied 


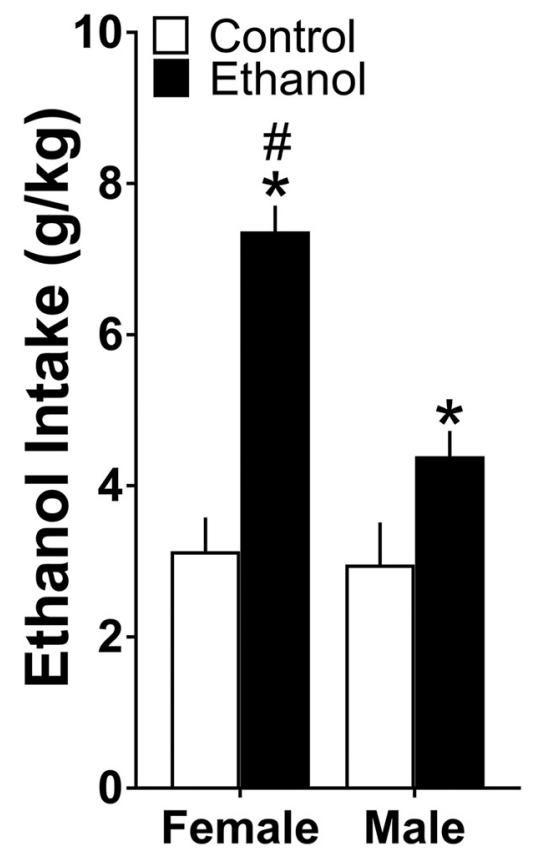

Figure 5. Maternal ethanol administration ( $2 \mathrm{~g} / \mathrm{kg} / \mathrm{d}$, E10-E15) compared with isocaloric control solution stimulated ethanol drinking over $24 \mathrm{~h}$ in both female and male adolescent offspring ( $n=10 /$ group/sex), with this effect significantly stronger in females. Data are mean \pm SEM. ${ }^{*} p<0.05$ versus control group. ${ }^{\#} p<0.05$ versus male group.

by disturbances in these behaviors in adolescent offspring. Analyses via a two-way ANOVA revealed a significant main effect of maternal treatment on their ethanol intake $\left(F_{(1,36)}=43.541, p=\right.$ 0.000 ), reflecting a significant increase in consumption in both females and males after in utero ethanol exposure versus control group, and also a significant main effect of sex on ethanol intake $\left(F_{(1,36)}=3.045, p=0.001\right)$ and a significant sex $\times$ maternal treatment interaction $\left(F_{(1,36)}=10.80, p=0.002\right)$ (Fig. 5), with no change in chow intake $\left(F_{(1,36)}=3.75, p=0.475,73 \pm 8.1\right.$ vs $68 \pm$ $7.3 \mathrm{kcal} / \mathrm{d})$ and water intake $\left(F_{(1,36)}=1.445, p=0.619,18 \pm 2.3\right.$ vs $20 \pm 1.9 \mathrm{ml} / \mathrm{d}$ ). Simple main effect analyses, revealing no difference between females and males in their ethanol intake under the control condition $(p=0.767)$, showed that ethanol-exposed females compared with males drink significantly more ethanol over $24 \mathrm{~h}(p=0.000)$, and direct comparisons between the females and males (via paired $t$ test) of maternal ethanol's stimulatory effect on ethanol intake showed this response to be significantly greater in females $\left(t_{(18)}=-3.63, p=0.002\right)$ (Fig. 5). Measures of BEC also revealed a significant main effect of treatment $\left(F_{(1,36)}=23.12, p=0.012\right)$ and $\operatorname{sex}\left(F_{(1,36)}=18.06, p=\right.$ $0.025)$ and a significant sex $\times$ treatment interaction $\left(F_{(1,36)}=\right.$ $10.19, p=0.004)$. While showing under control conditions no difference $(p=0.661)$ between the females $(65 \pm 5 \mathrm{mg} \%)$ and males (62 $\pm 8 \mathrm{mg} \%)$, simple main effect analyses showed ethanol-exposed females $(115 \pm 10 \mathrm{mg} \%)$ to have significantly higher BEC $(p=0.003)$ than the ethanol-exposed males $(80 \pm 9$ $\mathrm{mg} \%$ ), consistent with their greater ethanol intake.

Analysis via a two-way ANOVA of measures reflecting anxiety in a novel open field (Table 3 ) revealed in the offspring a significant main effect of treatment on freezing time $\left(F_{(1,22)}=19.45\right.$, $p=0.000)$ and time spent in the center $\left(F_{(1,22)}=11.94, p=\right.$ $0.002)$, with a significant effect of sex on freezing time $\left(F_{(1,22)}=\right.$ 7.06, $p=0.015)$ but no sex $\times$ treatment interaction for freezing time $\left(F_{(1,22)}=0.606, p=0.445\right)$ and no effect of sex on time spent in the center $\left(F_{(1,22)}=3.707, p=0.068\right)$. Simple main effect
Table 3. Effects of maternal ethanol administration versus control on anxiety (freezing time and time spent in center) and locomotor behavior (ambulatory counts and distance) in a novel open field in female and male adolescent offspring

\begin{tabular}{|c|c|c|c|c|}
\hline \multirow[b]{2}{*}{ Behavioral measures } & \multicolumn{2}{|l|}{ Female } & \multicolumn{2}{|l|}{ Male } \\
\hline & Control & Ethanol & Control & Ethanol \\
\hline Freezing time (s) & $137 \pm 3$ & $159 \pm 5^{*}$ & $151 \pm 4$ & $167 \pm 3^{*}$ \\
\hline Time spent in center (s) & $300 \pm 42$ & $197 \pm 20^{*}$ & $246 \pm 28$ & $130 \pm 35^{*}$ \\
\hline Ambulatory counts (no.) & $1204 \pm 128$ & $814 \pm 96^{*}$ & $979 \pm 57$ & $737 \pm 34^{*}$ \\
\hline Ambulatory distance $(\mathrm{cm})$ & $1452 \pm 119$ & $1124 \pm 81^{*}$ & $1232 \pm 69$ & $1041 \pm 37^{*}$ \\
\hline
\end{tabular}

analyses showed that maternal ethanol exposure versus control significantly increased freezing time in both females $(p=0.001)$ and males $(p=0.020)$ and decreased time spent in the center in both females $(p=0.029)$ and males $(p=0.019)$, suggesting an ethanol-induced increase in anxiety as previously reported (Hellemans et al., 2010; Elibol-Can et al., 2014). Analyses of locomotor activity (Table 3) revealed a significant main effect of maternal ethanol on ambulatory counts $\left(F_{(1,22)}=13.91, p=\right.$ $0.001)$ and ambulatory distance $\left(F_{(1,22)}=9.95, p=0.005\right)$. This reflected a decrease in locomotor behavior as previously shown (Carneiro et al., 2005), with reduced ambulatory counts in both females $(p=0.005)$ and males $(p=0.046)$, reduced distance in females $(p=0.009)$ but not males $(p=0.122)$, and no effect of sex on either counts $\left(F_{(1,22)}=3.49, p=0.076\right)$ or distance $\left(F_{(1,35)}=3.39, p=0.080\right)$. These results show that maternal ethanol administration increases ethanol intake and anxiety-like behavior in both female and male adolescent offspring along with reduced locomotor activity, and this effect on ethanol drinking but not anxiety or locomotor activity is significantly stronger in females.

\section{Maternal CCL2 administration increases CCL2/CCR2 and $\mathrm{MCH}$ expression and cell density in $\mathrm{LH}$ of the offspring} To test a possible involvement of the CCL2/CCR2 system in ethanol's stimulatory effect on MCH neurons in the LH, we administered CCL2 itself to pregnant rats to determine whether this chemokine has similar effects to ethanol on gene expression and neuronal density in the LH of adolescent offspring. Daily injections of CCL2 (4 or $8 \mu \mathrm{g} / \mathrm{kg} / \mathrm{d}, \mathrm{E} 10-\mathrm{E} 15$ ) compared with vehicle control had no effect on the dam's food intake $\left(F_{(2,48)}=1.601\right.$, $p=0.720,72 \pm 9$ vs $67 \pm 6$ vs $73 \pm 8 \mathrm{kcal} / \mathrm{d}$, respectively) or water intake $\left(F_{(2,48)}=1.712, p=0.520,21 \pm 4\right.$ vs $19 \pm 5 \mathrm{vs} 22 \pm 3 \mathrm{ml} / \mathrm{d}$, respectively), and it produced no change in her litters in terms of size $\left(F_{(2,48)}=2.110, p=0.190,12 \pm 4\right.$ vs $10 \pm 2$ vs $10 \pm 2$, respectively) and average body weight $\left(F_{(2,48)}=1.674, p=0.825\right.$, $5.78 \pm 1.01$ vs $6.4 \pm 2.12$ vs $6.5 \pm 1.89 \mathrm{~g}$, respectively), with no spontaneous abortions.

Analysis via a two-way ANOVA of gene expression in the LH of the female and male adolescent offspring revealed a significant main effect of maternal treatment on mRNA levels of CCR2 $\left(F_{(2,48)}=20.88, p=0.001\right)$ and $\operatorname{MCH}\left(F_{(2,48)}=29.24, p=0.000\right)$, showing a significant increase in their expression in females and males at both CCL2 doses. There was also a significant main effect of sex on mRNA levels of CCR2 $\left(F_{(1,48)}=19.94, p=0.000\right)$ and $\mathrm{MCH}\left(F_{(1,48)}=12.53, p=0.011\right)$ and a significant sex $\times$ maternal treatment interaction on mRNA levels of CCR2 $\left(F_{(2,48)}=\right.$ $5.331, p=0.008)$ and $\mathrm{MCH}\left(F_{(2,48)}=3.541, p=0.014\right)$ (Fig. $\left.6 A\right)$. A two-way ANOVA also revealed a significant main effect of maternal treatment on mRNA expression of CCL2 $\left(F_{(2,48)}=\right.$ $36.17, p=0.001)$, a significant main effect of $\operatorname{sex}\left(F_{(1,48)}=10.33\right.$, 
A
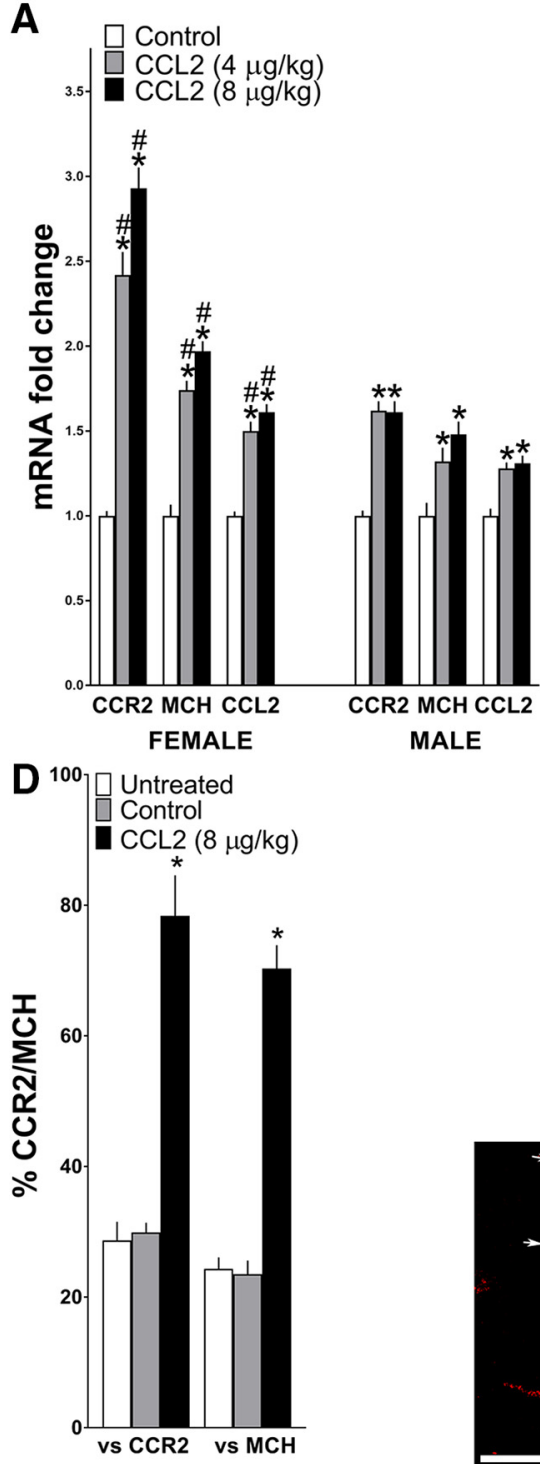

B 1
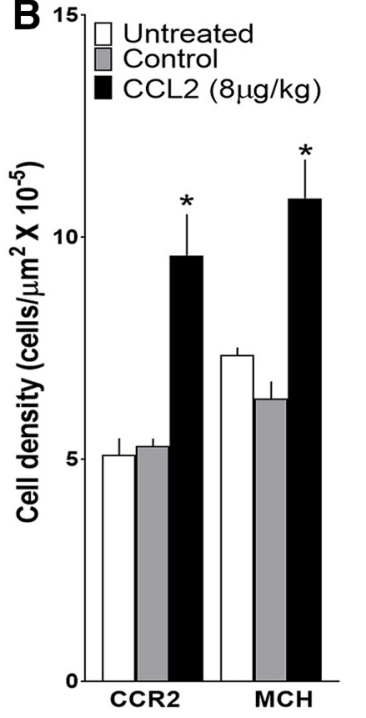

E
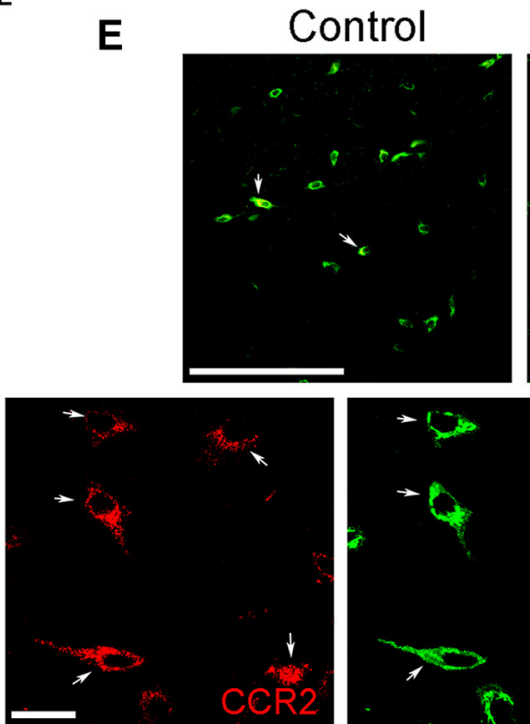

C
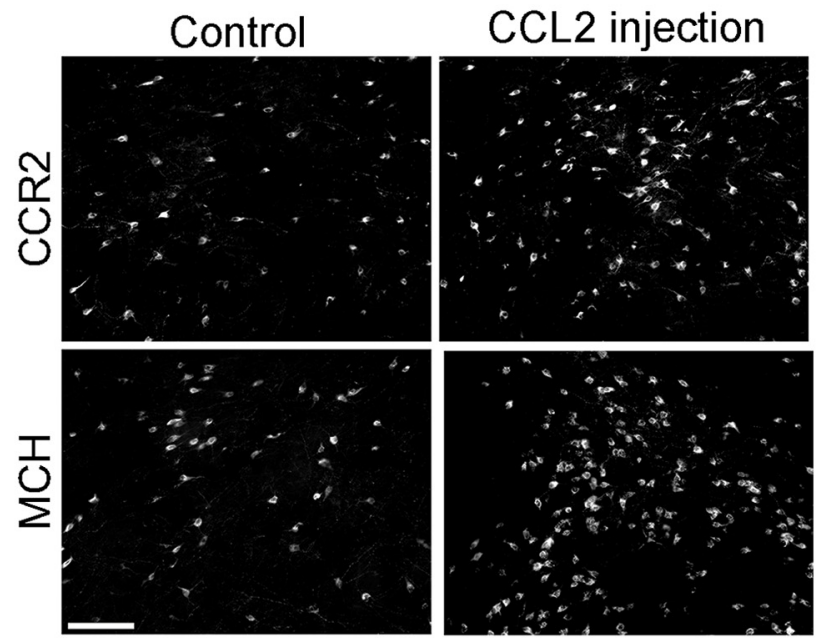

CCL2 injection

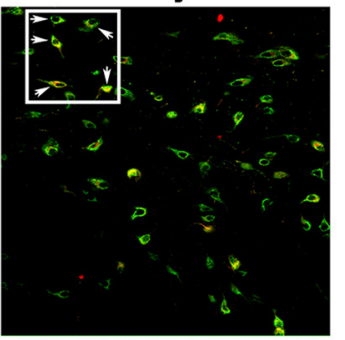

Figure 6. Maternal injection of CCL2 (4 and $8 \mu \mathrm{g} / \mathrm{kg} / \mathrm{d}$, E10 -E15) compared with vehicle control group affects in adolescent offspring the expression of CCR2, MCH, and CCL2, measured using qRT-PCR and represented in the figure as mRNA fold change compared with the control group (with average ratio scores given in parentheses), and the density of $C C R 2^{+}$and $M C H{ }^{+}$neurons in the LH measured using IF. $A$, CCL2 administration compared with control group ( $n=9 /$ group/sex) significantly increased in female offspring mRNA levels of MCH (control $=0.237 \pm 0.0155,4$ $\mu \mathrm{g} / \mathrm{kg} / \mathrm{d}=0.413 \pm 0.023$, and $8 \mu \mathrm{g} / \mathrm{kg} / \mathrm{d}=0.468 \pm 0.028$ ), CCR2 (control $=0.127 \pm 0.034,4 \mu \mathrm{g} / \mathrm{kg} / \mathrm{d}=0.308 \pm 0.041$, and $8 \mu \mathrm{g} / \mathrm{kg} / \mathrm{d}=0.373 \pm 0.046$ ), and CCL2 (control $=0.222 \pm$ $0.019,4 \mu \mathrm{g} / \mathrm{kg} / \mathrm{d}=0.333 \pm 0.018$, and $8 \mu \mathrm{g} / \mathrm{kg} / \mathrm{d}=0.358 \pm 0.017)$ and in male offspring mRNA levels of MCH (control $=0.241 \pm 0.018,4 \mu \mathrm{g} / \mathrm{kg} / \mathrm{d}=0.319 \pm 0.026$, and $8 \mu \mathrm{g} / \mathrm{kg} / \mathrm{d}=$ $0.356 \pm 0.027$ ), CCR2 (control $=0.123 \pm 0.027,4 \mu \mathrm{g} / \mathrm{kg} / \mathrm{d}=0.199 \pm 0.012$, and $8 \mu \mathrm{g} / \mathrm{kg} / \mathrm{d}=0.198 \pm 0.013$ ), and CCL2 (control $=0.225 \pm 0.009,4 \mu \mathrm{g} / \mathrm{kg} / \mathrm{d}=0.289 \pm 0.010$, and 8 $\mu \mathrm{g} / \mathrm{kg} / \mathrm{d}=0.295 \pm 0.013$ ), with a significantly stronger effect in females as indicated in particular by an unusually large increase in CCR2 mRNA. $B, C C L 2$ injection increased the density of CCR2 + and $\mathrm{MCH}^{+}$neurons in female offspring. $\boldsymbol{C}$, This effect of $\mathrm{CCL} 2$ versus control on cell density is illustrated in representative immunostaining images of single-labeled cells. $\boldsymbol{D}$, CCL2 injection increased the density of $\mathrm{CCR2}{ }^{+} / \mathrm{MCH}^{+}$double-labeled neurons in the LH of the female offspring ( $n=7 /$ group). $\boldsymbol{E}$, This effect of CCL2 versus control on double-labeled neurons is illustrated in the confocal images showing $\mathrm{CCR2}^{+}$(red) and $\mathrm{MCH}^{+}$(green) single-labeled neurons and CCR2 ${ }^{+} / \mathrm{MCH}^{+}$(yellow) double-labeled neurons in the LH. Top, A few CCR2 ${ }^{+} / \mathrm{MCH}^{+}$neurons in control offspring and many in CCL2-treated offspring (arrows), with those in the white square (bottom) at higher magnification for CCR2 ${ }^{+}$(left) and $\mathrm{MCH}^{+}$(middle) single-labeled neurons and for $\mathrm{CCR2}^{+} / \mathrm{MCH}^{+}$ (right) double-labeled neurons (yellow or red/green). Scale bars, $200 \mu \mathrm{m}$. Data are mean \pm SEM. ${ }^{*} p<0.05$ versus control groups. ${ }^{\#} p<0.05$ versus male groups.

$p=0.02)$, and a significant sex $\times$ maternal treatment interaction $\left(F_{(2,48)}=3.28, p=0.046\right)$ (Fig. $\left.6 A\right)$. Simple main effect analyses showed that there were no differences between the females and males under control conditions in their expression of CCR2 ( $p=$ $0.911), \mathrm{MCH}(p=0.717)$, and CCL2 $(p=0.872)$ and no differences between the effects of the two CCL2 doses on CCR2 ( $p=$ $0.089)$ and $\mathrm{MCH}(p=0.102)$ in females and CCR2 $(p=0.986)$ and $\mathrm{MCH}(p=0.270)$ in males. However, these measures of mRNA levels in CCL2-treated offspring ( 4 and $8 \mu \mathrm{g} / \mathrm{kg} / \mathrm{d}$ ) were significantly higher in the females than males at both doses for CCR2 $(p=0.005$ and $p=0.001)$ and $\mathrm{MCH}(p=0.007$ and $p=$
$0.001)$ as well as CCL2 ( $p=0.021$ and $p=0.002)$. Direct comparisons between the females and males (via paired $t$ test) of ethanol's stimulatory effects on mRNA levels in the LH showed that the CCL2-induced changes compared with control were significantly greater in the females at both the 4 and $8 \mu \mathrm{g} / \mathrm{kg} / \mathrm{d}$ doses of CCL2. This was evident for the measures of CCR2 $\left(t_{(16)}=\right.$ $-2.346, p=0.043$ and $\left.t_{(16)}=-3.857, p=0.002\right), \mathrm{MCH}\left(t_{(16)}=\right.$ $-2.241, p=0.042$ and $\left.t_{(16)}=-2.634, p=0.018\right)$, and CCL2 $\left(t_{(16)}=-1.841, p=0.044\right.$ and $\left.t_{(16)}=-2.566, p=0.021\right)$, with the CCL2-induced increase in CCR2 mRNA unusually large and distinctive in female offspring (Fig. 6A). 
Analysis via a one-way ANOVA of cell density in the LH of female adolescent offspring revealed a significant main effect of maternal treatment on single-labeled CCR ${ }^{+}{ }_{\left(F_{(2,20)}\right.}=18.54$, $p=0.000)$ and $\mathrm{MCH}^{+}\left(F_{(2,20)}=14.93, p=0.000\right)$ neurons (Fig. $6 B$ ), as illustrated in the photomicrographs (Fig. 6C). Post hoc analyses showed that CCL2 at the higher dose of $8 \mu \mathrm{g} / \mathrm{kg} / \mathrm{d}$ (data were lost at the lower dose) caused a significant increase in the density of CCR $2{ }^{+}$neurons compared with the control $(81 \%, p=$ $0.000)$ and untreated $(77 \%, p=0.000)$ groups, with no difference between the two control groups $(p=0.0875)$, and also in the density of $\mathrm{MCH}^{+}$neurons compared with the control $(71 \%, p=$ $0.000)$ and untreated $(65 \%, p=0.000)$ groups, again with no difference between the two control groups $(p=0.0830)$. Maternal CCL2 administration also had a significant main effect on the CCR2 ${ }^{+} / \mathrm{MCH}^{+}$double-labeled neurons relative to total singlelabeled CCR2 ${ }^{+}\left(F_{(2,20)}=49.75, p=0.000\right)$ and $\mathrm{MCH}^{+}\left(F_{(2,20)}=\right.$ $103.29 p=0.000$ ) neurons (Fig. $6 D$ ), as shown in the confocal images (Fig. 6E). Post hoc analyses showed that maternal CCL2 administration increased the density of $\mathrm{CCR} 2{ }^{+} / \mathrm{MCH}^{+}$relative to total CCR $2{ }^{+}$neurons compared with the control $(162 \%, p=$ $0.000)$ or untreated $(173 \%, p=0.000)$ groups, with no difference between the two control groups $(p=0.0835)$, and also the density of $\mathrm{CCR} 2{ }^{+} / \mathrm{MCH}^{+}$relative to total $\mathrm{MCH}^{+}$neurons compared with the control $(199 \%, p=0.000)$ and untreated $(189 \%$, $p=0.000)$ groups, again with no difference between the two control groups $(p=0.0729)$. Although male offspring were not examined for this effect of maternal CCL2 administration on $\mathrm{CCR}_{2}{ }^{+}$and $\mathrm{MCH}^{+}$neurons, our findings here with measurements of gene expression led us to expect that this measure of cell density will also be stimulated by CCL2 in a sex-dependent manner, based on our prior studies (Chang et al., 2008, 2013) showing cell density and gene expression to respond similarly. Thus, maternal administration of CCL2 has similar effects to ethanol on both the CCL2/CCR2 and MCH systems in the LH of adolescent offspring, stimulating their expression in a sexually dimorphic manner while also increasing their cell density and percentage of $\mathrm{CCR} 2{ }^{+}$neurons that double-label MCH.

\section{Maternal CCL2 administration increases ethanol drinking and anxiety in female and male adolescent offspring}

The question addressed here is whether maternal administration of CCL2 ( 4 or $8 \mu \mathrm{g} / \mathrm{kg} / \mathrm{d}, \mathrm{E} 10-\mathrm{E} 15$ ) that stimulates LH neurons in the offspring also has sexually dimorphic effects on their ethanol drinking behavior, similar to that produced by maternal administration of ethanol. A two-way ANOVA revealed a significant main effect of maternal treatment on ethanol intake $\left(F_{(2,54)}=\right.$ 61.752, $p=0.000$ ) reflecting an increase in drinking in both females and males, along with a significant main effect of sex on ethanol intake $\left(F_{(1,54)}=10.516, p=0.02\right)$ and a significant sex $\times$ maternal treatment interaction $\left(F_{(2,54)}=11.307, p=0.000\right)$ (Fig. $7)$. There was no main effect, however, of maternal CCL2 treatment on water intake $\left(F_{(2,54)}=0.069, p=0.934\right)$, with control females $(19.3 \pm 1.27 \mathrm{ml} / \mathrm{d})$ and males $(18.7 \pm 0.75 \mathrm{ml} / \mathrm{d})$ similar to CCL2 at $4 \mu \mathrm{g} / \mathrm{kg} / \mathrm{d}$ for females $(18.5 \pm 1.28 \mathrm{ml} / \mathrm{d})$ and males $(19.8 \pm 0.88 \mathrm{ml} / \mathrm{d})$ and to CCL2 at $8 \mu \mathrm{g} / \mathrm{kg} / \mathrm{d}$ for females $(18.0 \pm$ $0.91 \mathrm{ml} / \mathrm{d})$ and males $(19.9 \pm 0.94 \mathrm{ml} / \mathrm{d})$. There was also no main effect of maternal CCL2 on food intake $\left(F_{(2,53)}=1.23, p=\right.$ $0.0231)$, with control females $(71 \pm 9.1 \mathrm{kcal} / \mathrm{d})$ and males $(67 \pm$ $5.9 \mathrm{kcal} / \mathrm{d})$ similar to CCL2 at $4 \mu \mathrm{g} / \mathrm{kg} / \mathrm{d}$ for females $(75 \pm 8.1$ $\mathrm{kcal} / \mathrm{d})$ and males $(68 \pm 5.1 \mathrm{kcal} / \mathrm{d})$ and to CCL2 at $8 \mu \mathrm{g} / \mathrm{kg} / \mathrm{d}$ for females $(70 \pm 8.1 \mathrm{kcal} / \mathrm{d})$ and males $(66 \pm 8.1 \mathrm{kcal} / \mathrm{d})$. Whereas simple main effect analyses of ethanol intake revealed no difference between the female and male offspring under control con-

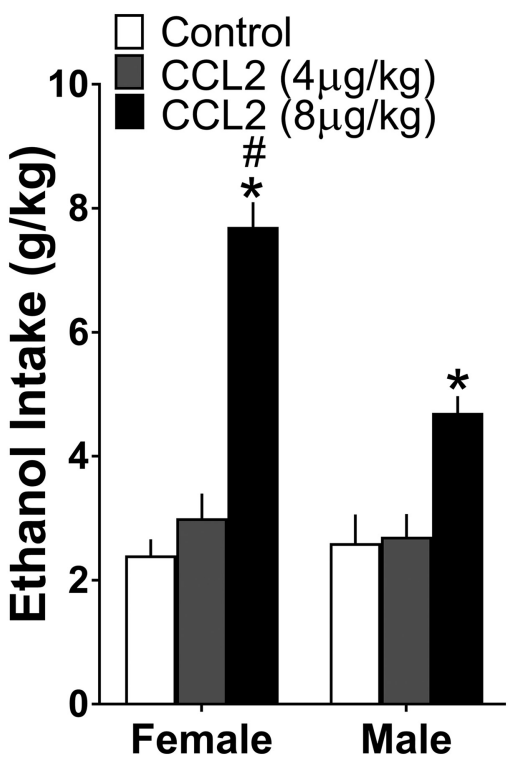

Figure 7. Maternal injection of CCL2 (4 or $8 \mu \mathrm{g} / \mathrm{kg} / \mathrm{d}$, E10-E15) compared with vehicle control group, like ethanol administration stimulated ethanol drinking over $24 \mathrm{~h}$ period in both female and male adolescent offspring ( $n=10 / \mathrm{group} / \mathrm{sex}$ ), with this effect significantly stronger in females. Data are mean \pm SEM. ${ }^{*} p<0.05$ versus control group. ${ }^{\#} p<0.05$ versus male group.

ditions $(p=0.591)$ or in response to CCL2 at $4 \mu \mathrm{g} / \mathrm{kg} / \mathrm{d}(p=$ $0.659)$, the female offspring from the CCL2 group at $8 \mu \mathrm{g} / \mathrm{kg} / \mathrm{d}$ drank significantly more ethanol than the males $(p=0.000)$ (Fig. 7 ). Also, direct comparisons between the females and males (via paired $t$ test) of their CCL2-induced increase in ethanol intake showed this effect to be significantly greater in females than males when comparing CCL2 at $8 \mu \mathrm{g} / \mathrm{kg} / \mathrm{d}$ to the control $\left(t_{(18)}=-4.98\right.$, $p=0.000)$, but not when comparing CCL2 at $4 \mu \mathrm{g} / \mathrm{kg} / \mathrm{d}$ to the control $\left(t_{(18)}=-0.654, p=0.521\right)$. The measures of BEC similarly revealed a significant main effect of treatment $\left(F_{(2,54)}=\right.$ 23.012, $p=0.002)$ and $\operatorname{sex}\left(F_{(1,54)}=15.452, p=0.019\right)$ and a significant sex $\times$ treatment interaction $\left(F_{(2,54)}=10.045, p=\right.$ $0.022)$, and the simple main effect analyses revealing no difference between females ( $58 \pm 7 \mathrm{mg} \%$ ) and males (50 $\pm 7 \mathrm{mg} \%$ ) under control conditions ( $p=0.496)$ showed the ethanolexposed females $(115 \pm 10 \mathrm{mg} \%)$ compared with ethanolexposed males $(76 \pm 6 \mathrm{mg} \%)$ to have significantly higher BEC ( $p=0.0189)$, consistent with their higher ethanol intake.

The female and male adolescent offspring were also tested in the novel open field to assess the effect of maternal CCL2 administration on anxiety-like and locomotor behavior. Analysis of the anxiety measures via a two-way ANOVA revealed a significant main effect of maternal treatment on freezing time $\left(F_{(2,35)}=\right.$ 19.47, $p=0.000)$ and time spent in the center $\left(F_{(2,35)}=7.025\right.$, $p=0.003)$, with sex having a significant main effect on time spent in the center $\left(F_{(1,35)}=7.75, p=0.009\right)$ but not freezing time $\left(F_{(1,35)}=2.322, p=0.137\right)$ (Table 4$)$. Simple main effect analyses showed that, compared with vehicle control, maternal CCL2 administration, like ethanol, significantly increased freezing time in both the females at $4 \mu \mathrm{g} / \mathrm{kg} / \mathrm{d}(p=0.001)$ and $8 \mu \mathrm{g} / \mathrm{kg} / \mathrm{d}(p=$ $0.001)$ and the males at $4 \mu \mathrm{g} / \mathrm{kg} / \mathrm{d}(p=0.001)$ and $8 \mu \mathrm{g} / \mathrm{kg} / \mathrm{d}(p=$ $0.009)$ and significantly decreased the time spent in the center in the females at $8 \mu \mathrm{g} / \mathrm{kg} / \mathrm{d}(p=0.049)$ but not $4 \mu \mathrm{g} / \mathrm{kg} / \mathrm{d}(p=$ $0.188)$ and the males at both $4 \mu \mathrm{g} / \mathrm{kg} / \mathrm{d}(p=0.004)$ and $8 \mu \mathrm{g} / \mathrm{kg} / \mathrm{d}$ $(p=0.010)$, with no significant differences detected between the two CCL2 doses on freezing time, for females $(p=0.295)$ and 
Table 4. Effects of maternal CCL2 injection versus control on anxiety (freezing time and time spent in center) and locomotor behavior (ambulatory counts and distance) in a novel open field in female and male adolescent offspring

\begin{tabular}{|c|c|c|c|c|c|c|}
\hline \multirow[b]{2}{*}{ Behavioral measures } & \multicolumn{3}{|l|}{ Female } & \multicolumn{3}{|l|}{ Male } \\
\hline & Control & CCL2 (4 $\mu \mathrm{g} / \mathrm{kg})$ & CCL2 $(8 \mu \mathrm{g} / \mathrm{kg})$ & Control & CCL2 (4 $\mu \mathrm{g} / \mathrm{kg})$ & CCL2 $(8 \mu \mathrm{g} / \mathrm{kg})$ \\
\hline Freezing time (s) & $125 \pm 2$ & $149 \pm 4^{*}$ & $144 \pm 2^{*}$ & $133 \pm 2$ & $151 \pm 6^{*}$ & $147 \pm 4^{*}$ \\
\hline Time spent in center $(s)$ & $306 \pm 32$ & $243 \pm 38$ & $218 \pm 26^{*}$ & $282 \pm 17$ & $188 \pm 26^{*}$ & $195 \pm 23^{*}$ \\
\hline Ambulatory counts (no.) & $1588 \pm 68$ & $1098 \pm 85^{*}$ & $1047 \pm 71^{*}$ & $1285 \pm 116$ & $872 \pm 64^{*}$ & $935 \pm 117^{*}$ \\
\hline Ambulatory distance $(\mathrm{cm})$ & $1816 \pm 64$ & $1359 \pm 101^{*}$ & $1239 \pm 81^{*}$ & $1516 \pm 130$ & $1070 \pm 71^{*}$ & $1158 \pm 95^{*}$ \\
\hline
\end{tabular}

${ }^{*} p<0.05$ versus control group.

males $(p=0.515)$, and on time spent in the center, for females $(p=0.521)$ and males $(p=0.831)$. Similar analyses of locomotor activity (Table 4 ) revealed a significant main effect of maternal treatment on ambulatory counts $\left(F_{(2,35)}=19.34, p=0.000\right)$ and ambulatory distance $\left(F_{(2,35)}=16.24, p=0.000\right)$ and a significant main effect of sex on counts $\left(F_{(1,35)}=9.72, p=0.004\right)$ and distance $\left(F_{(1,35)}=8.50, p=0.006\right)$, with no sex $\times$ maternal treatment interaction for either counts $\left(F_{(2,35)}=0.639, p=\right.$ $0.534)$ or distance $\left(F_{(2,35)}=0.845, p=0.438\right)$. This reflected a significant decrease in ambulatory counts, in both females at 4 $\mu \mathrm{g} / \mathrm{kg} / \mathrm{d}(p=0.000)$ and $8 \mu \mathrm{g} / \mathrm{kg} / \mathrm{d}(p=0.000)$ and males at 4 $\mu \mathrm{g} / \mathrm{kg} / \mathrm{d}(p=0.001)$ and $8 \mu \mathrm{g} / \mathrm{kg} / \mathrm{d}(p=0.007)$, and also ambulatory distance, in both females at $4 \mu \mathrm{g} / \mathrm{kg} / \mathrm{d}(p=0.001)$ and 8 $\mu \mathrm{g} / \mathrm{kg} / \mathrm{d}(p=0.000)$ and males at $4 \mu \mathrm{g} / \mathrm{kg} / \mathrm{d}(p=0.002)$ and 8 $\mu \mathrm{g} / \mathrm{kg} / \mathrm{d}(p=0.000)$, with control females compared with control males having higher ambulatory counts $(p=0.014)$ and distance $(p=0.028)$. The effects of CCL2 were similar at both doses, with no differences detected between their effects on ambulatory distance, in females $(p=0.366)$ and males $(p=0.520)$, and on ambulatory counts, in females $(p=0.675)$ and males $(p=0.611)$. Thus, maternal administration of CCL2, like ethanol, increases ethanol intake and anxiety-like behavior in both female and male adolescent offspring while reducing locomotor activity, and this effect on ethanol intake but not anxiety or locomotor behavior is sexually dimorphic, significantly stronger in females.

\section{CCL2 neurons in LH are closely related to MCH and CCR2} neurons when stimulated by maternal ethanol exposure

To further investigate the endogenous CCL2/CCR2 system in the LH, we used single-labeling IF and double-labeling IF with confocal microscopy to characterize in adolescent female offspring the $\mathrm{CCL} 2{ }^{+}$cells, their relationship to the $\mathrm{MCH}^{+}$neurons colabeling CCR2, and their responsiveness to maternal administration of ethanol at a moderate dose. We found under control conditions that a majority of the $\mathrm{CCL} 2{ }^{+}$cells in the $\mathrm{LH}$ as described for CCR ${ }^{+}$cells (Chang et al., 2015) were neurons, showing colocalization with the neuronal marker NeuN but not the astrocyte marker GFAP or microglia marker Iba-1. Whereas maternal administration of ethanol $(2 \mathrm{~g} / \mathrm{kg} / \mathrm{d})$ compared with isocaloric control (paired $t$ test) had no effect on the density of GFAP ${ }^{+}$ and Iba- $1^{+}$cells (Table 5) as described previously (Chang et al., 2012, 2015) and produced no detectable colocalization of CCL2 as well as CCR2 with these glia markers (Fig. $8 A$ ), it significantly stimulated as previously shown for CCR2 (Chang et al., 2015) the density of CCL2 ${ }^{+}$cells that colabeled NeuN relative to total single-labeled CCL2 ${ }^{+}$cells $\left(t_{(12)}=-7.971, p=0.000\right)$, with the percentage increased to $>90 \%$ (Table 5 ).

Interestingly, further analyses of the CCL $2^{+}$cells in the adolescent offspring revealed two distinct types (Fig. $8 B$ ), both of which were neurons that colabeled NeuN but were very different in terms of their size, appearance, and anatomical distribution.
Table 5. Effects of maternal ethanol administration on density of GFAP ${ }^{+}$and Iba- ${ }^{+}$single-labeled cells and on $\mathrm{CCL} 2{ }^{+} / \mathrm{NeuN}^{+}$double-labeled neurons in the LH of adolescent offspring

\begin{tabular}{lll}
\hline Labeled cells in LH & Control & Ethanol \\
\hline GFAP & $0.91 \times 10^{-4} \pm 0.9 \times 10^{-7}$ & $0.93 \times 10^{-4} \pm 0.4 \times 10^{-7}$ \\
lba-1 & $0.95 \times 10^{-4} \pm 2.2 \times 10^{-5}$ & $1.06 \times 10^{-3} \pm 1.3 \times 10^{-5}$ \\
CCL2/NeuN versus & $0.522 \pm 0.052$ & $0.936 \pm 0.014^{*}$ \\
$\quad$ total CCL2 (\%) & & \\
\hline$*_{p}<0.05$ ver &
\end{tabular}

${ }^{*} p<0.05$ versus control group.

Under control conditions, $>60 \%$ of these CCL2 ${ }^{+}$neurons were large (arrow) with long processes and most heavily concentrated in the $\mathrm{LH}$, whereas $40 \%$ were small (arrowhead) with few processes and were less dense and diffusely scattered throughout the entire hypothalamus. Maternal administration of ethanol compared with control group showed (via paired $t$ test) that both the large and the small CCL2 ${ }^{+} / \mathrm{NeuN}^{+}$double-labeled neurons were significantly stimulated by ethanol (Fig. $8 C$ ), as illustrated in the confocal images (Fig. $8 D$ ). It increased to $98 \%$ the percentage of large CCL2 ${ }^{+}$cells that were neurons, as shown by relating the density of large CCL2 ${ }^{+} / \mathrm{NeuN}^{+}$double-labeled cells to the total large CCL2 ${ }^{+}$single-labeled cells $\left(t_{(12)}=-6.384, p=0.000\right)$, and also increased to $85 \%$ the percentage of small CCL2 ${ }^{+}$cells there were neurons, as shown by relating the density of small CCL $2^{+}$/ $\mathrm{NeuN}^{+}$double-labeled cells to the total small CCL2 ${ }^{+}$singlelabeled cells $\left(t_{(12)}=-11.065, p=0.000\right)$. Whereas the small $\mathrm{CCL}_{2}{ }^{+}$neurons in the $\mathrm{LH}$ showed little colocalization with CCR 2 and $\mathrm{MCH}$ under any condition, the large CCL2 ${ }^{+}$neurons that were similar in appearance to the $\mathrm{CCR} 2{ }^{+}$and $\mathrm{MCH}^{+}$neurons exhibited colocalization that was markedly affected by ethanol. Maternal administration of ethanol versus control significantly increased the percentage of large CCL $2^{+} / \mathrm{CCR} 2^{+}$ double-labeled neurons relative to total large $\mathrm{CCL}^{+}{ }^{+} t_{(12)}=$ $-7.638, p=0.000)$ or CCR ${ }^{+}\left(t_{(12)}=-8.460, p=0.000\right)$ singlelabeled neurons (Fig. $8 E, F$ ), and the percentage of large CCL2 ${ }^{+}$/ $\mathrm{MCH}^{+}$double-labeled neurons relative to total large CCL2 ${ }^{+}$ $\left.t_{(12)}=-10.047, p=0.000\right)$ or $\mathrm{MCH}^{+}\left(t_{(12)}=-8.366, p=\right.$ 0.001 ) single-labeled neurons (Fig. $8 G, H$ ), with the $40 \%$ of CCL2 neurons colabeling $\mathrm{MCH}$, suggesting that other neurochemicals are likely to be expressed in these CCL2 neurons. While the small $\mathrm{CCL}_{2}{ }^{+}$neurons failed to express $\mathrm{MCH}$, they were closely related to this peptide in a different manner, often found only in ethanolexposed offspring to exist in close proximity to the $\mathrm{MCH}^{+}$neurons, located immediately adjacent to and even surrounding these large neurons as illustrated in the far right confocal image (Fig. $8 \mathrm{H}$ ). These findings in the $\mathrm{LH}$ of adolescent offspring, while descriptive and needing confirmation with unbiased morphological analyses that can provide quantitative data, suggest that the primary effect of maternal ethanol administration at a moderate dose is on CCL2 in neurons, both large MCH neurons that colocalize CCR2 as well as CCL2 and small CCL2 neurons lying close to these MCH neurons that colabel CCR2. 
A
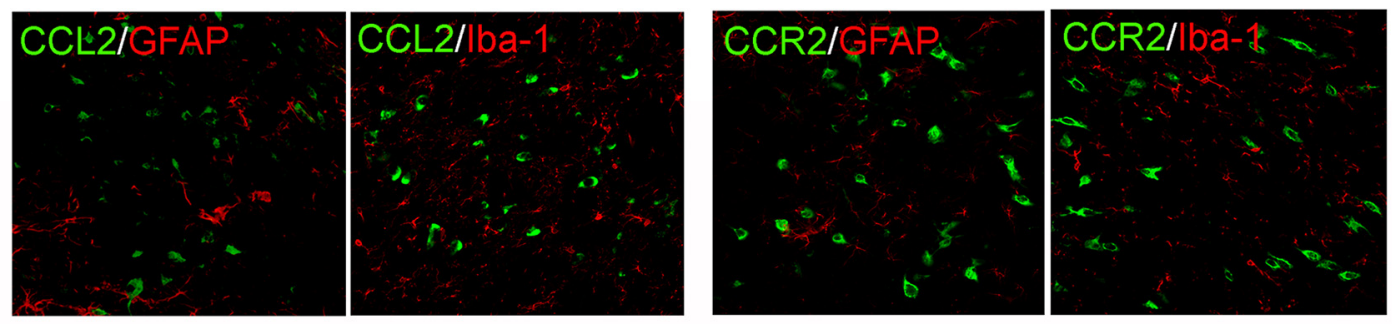

B

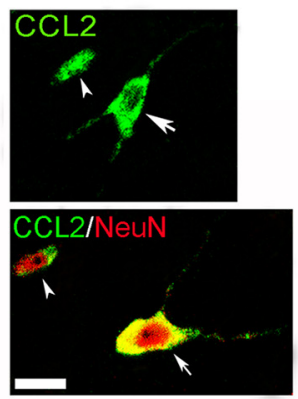

C

D
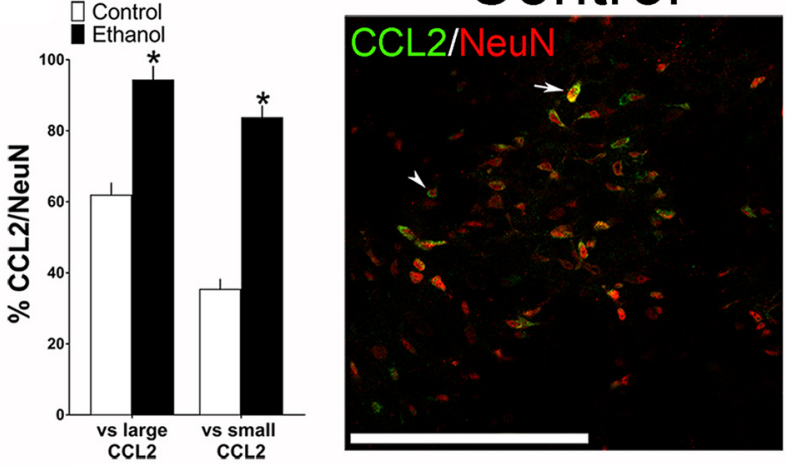

Control

E

$\mathbf{F}$

Control

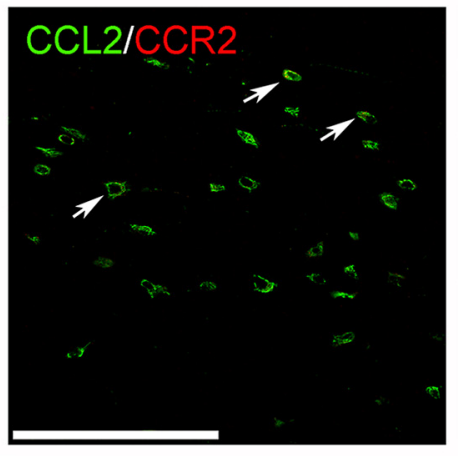

White Square

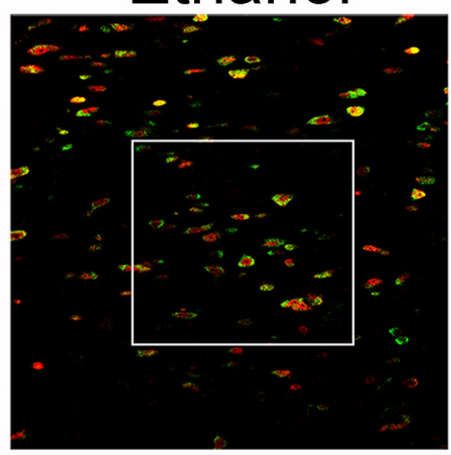

Ethanol

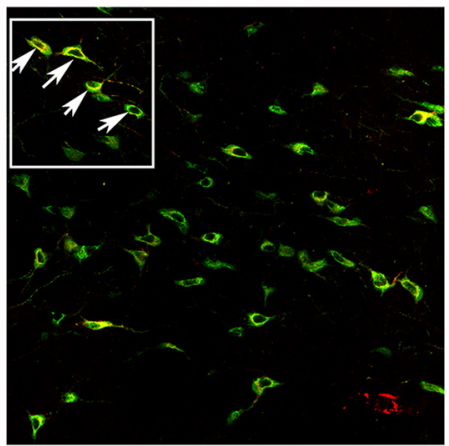

White Square

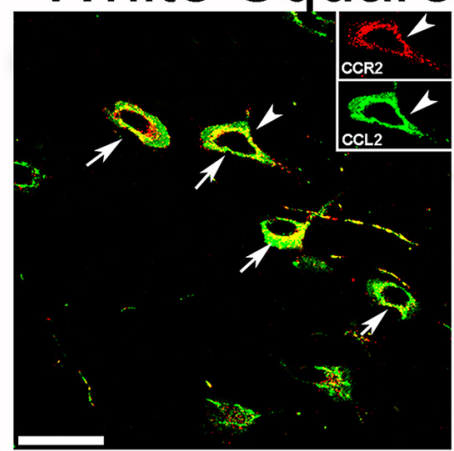

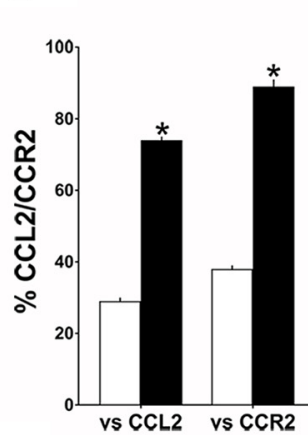

$\mathrm{H}$

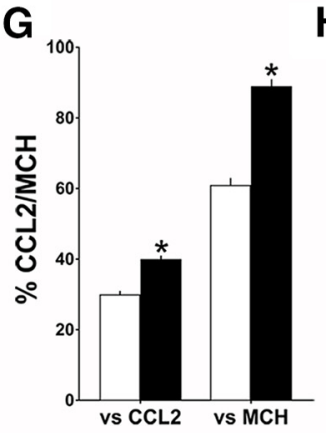

Control

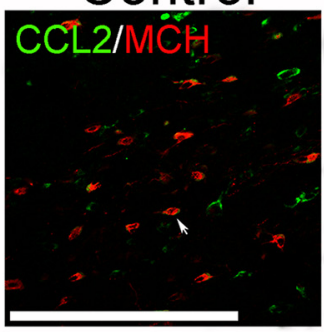

Ethanol

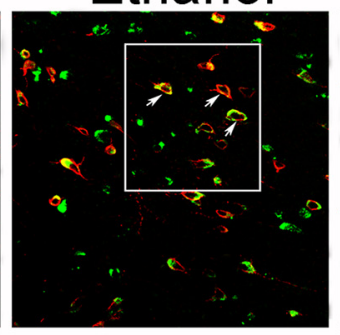

White Square
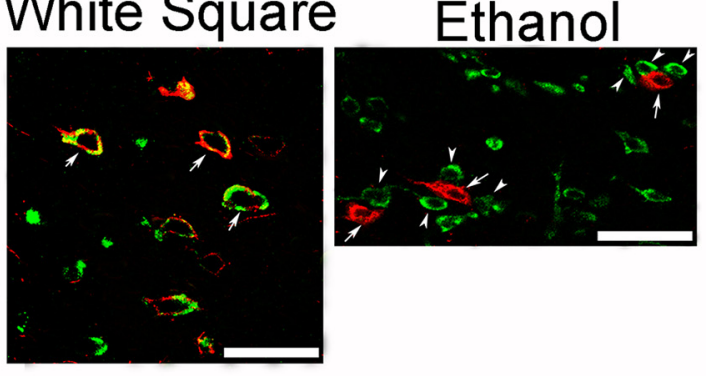

Figure 8. Maternal ethanol administration (2 g/kg/d, E10-E15) compared with control solution, while having no effect on glia, alters the density of both large and small CCL2 ${ }^{+}$neurons in the LH, as assessed by IF in female adolescent offspring ( $n=7 /$ group). $\boldsymbol{A}$, Confocal images show in ethanol-treated offspring no colocalization of CCL2 or CCR2 ( $\mathrm{green}$ ) with the markers of astrocytes (GFAP) and microglia (Iba-1) (red). B, Two confocal images provide typical examples of the large (arrow) and small (arrowhead) CCL2 ${ }^{+}$single-labeled cells (green) in the LH (top) and of large (arrow) and small (arrowhead) $\mathrm{CCL2}^{+}$neurons that double-labeled the neuronal marker NeuN (bottom), with CCL2 (green) and NeuN (red) revealing CCL2 ${ }^{+} / \mathrm{NeuN}^{+}$double-labeled neurons that are large (yellow/red center) or small (green/red center). C, Maternal ethanol administration increased the density of both large and small CCL2 ${ }^{+}$neurons that double-labeled NeuN, as indicated by the increased percentage of both large and small CCL2 ${ }^{+} / \mathrm{NeuN}^{+}$double-labeled neurons relative to total large or total small CCL2 ${ }^{+}$single-labeled cells, respectively. $\boldsymbol{D}$, Representative confocal images show few large (arrow) and few small (arrowhead) $\mathrm{CCL}^{+}$(green) neurons that colabeled NeuN (red) in control offspring (left) but many $\mathrm{CCL}^{+} / \mathrm{NeuN}^{+}$neurons (green/red center) in ethanol-exposed offspring (middle), with those in the white square illustrated at higher magnification (right). $\boldsymbol{E}$, Maternal ethanol administration increased the density of $\mathrm{CCL}^{+}{ }^{+}$neurons, mostly large, that colabeled CCR2, as indicated by the increased percentage of large $\mathrm{CCL}^{+} / \mathrm{CCR2}{ }^{+}$double-labeled neurons relative to total large $\mathrm{CCL2}^{+}$or $\mathrm{CCR2}^{+}$single-labeled neurons. $\boldsymbol{F}$, Representative confocal images, illustrating mostly large CCL2 ${ }^{+}$(green) and $\mathrm{CCR2}^{+}$(red) neurons that were double-labeled (green/yellow), show some $\mathrm{CCL2}^{+} / \mathrm{CCR2}^{+}$neurons (arrow) in control offspring (left) and many more $\mathrm{CCL}^{+} / \mathrm{CCR2}^{+}$neurons (arrow) in ethanol-treated offspring (middle), with those in the white square illustrated at higher magnification (right). $\mathbf{G}$, Maternal ethanol administration increased the density of $\mathrm{CCL}^{+}$neurons, mostly large, that colabeled $\mathrm{MCH}$, as indicated by the increased percentage of large $\mathrm{CCL}^{+} / \mathrm{MCH}^{+}($Figure legend $\mathrm{continues}$.) 


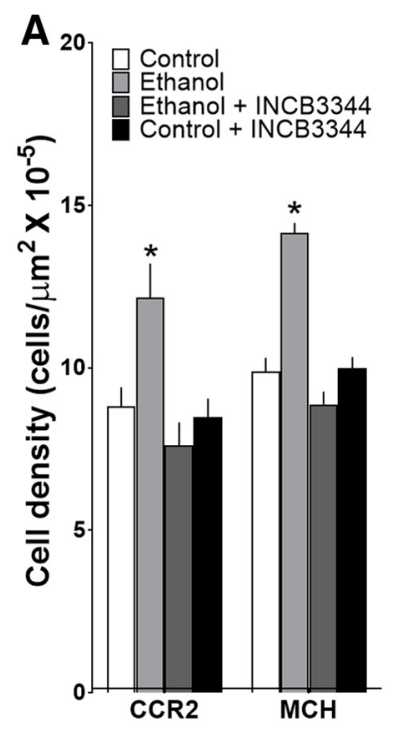

B
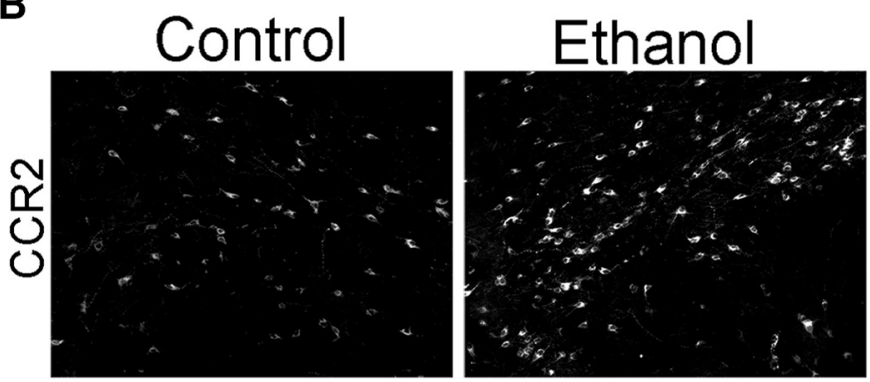

Ethanol + INCB3344
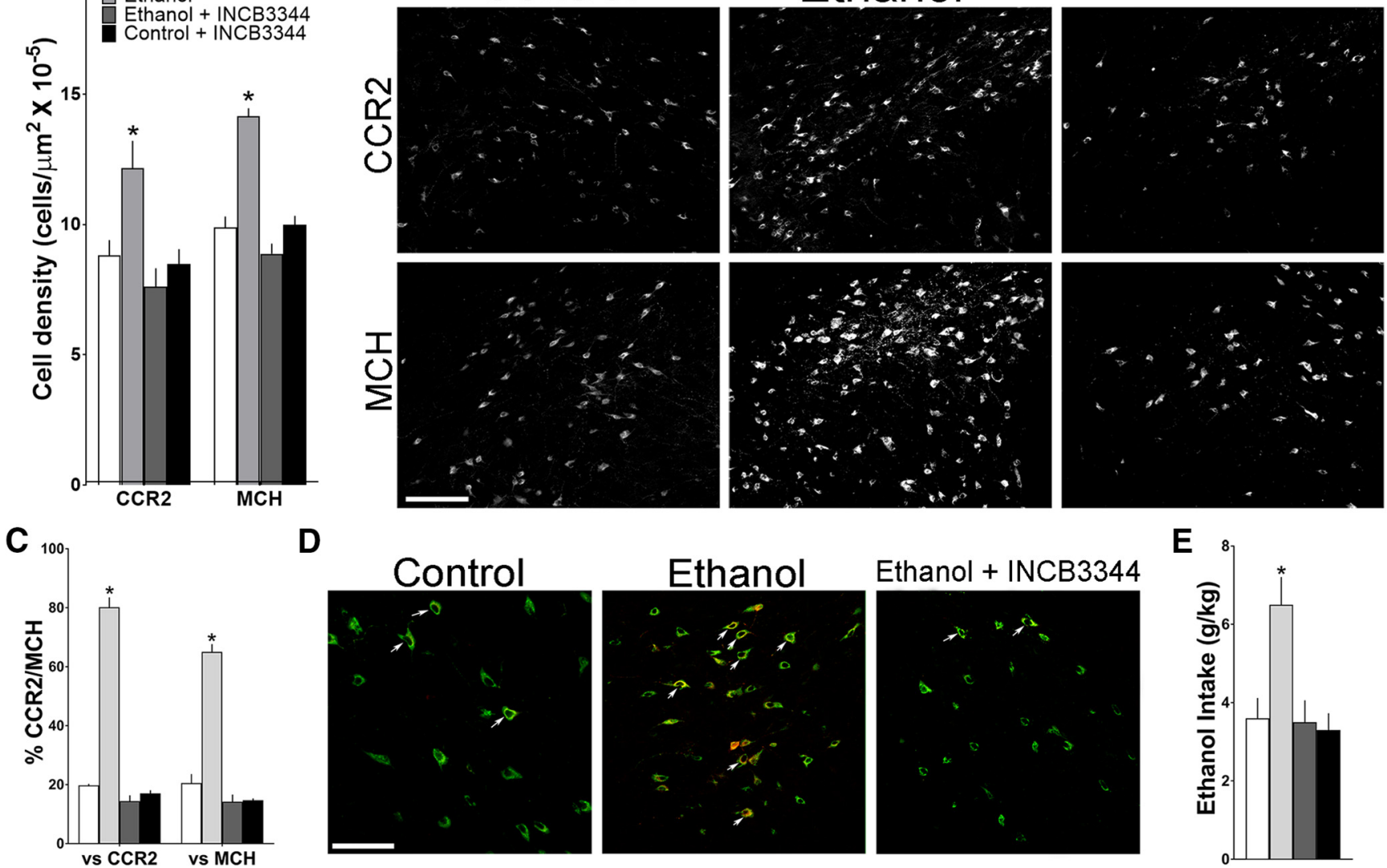

Figure 9. Maternal injection of a CCR2 antagonist INCB3344 $(1 \mathrm{mg} / \mathrm{kg} / \mathrm{d})$ during the period of maternal ethanol administration (2 $\mathrm{g} / \mathrm{kg} / \mathrm{d}, \mathrm{E} 10$-E15) prevents the stimulatory effect of ethanol on $\mathrm{CCR2}^{+}$and $\mathrm{MCH}^{+}$single-labeled neurons and $\mathrm{CCR2}^{+} / \mathrm{MCH}^{+}$double-labeled neurons in the $\mathrm{LH}$ of female adolescent offspring as measured by IF. $A$, Ethanol treatment increased the density of $\mathrm{CCR2}^{+}$and $\mathrm{MCH}^{+}$neurons compared with control, whereas INCB3344 treatment blocks this effect of ethanol in the offspring ( $n=7 /$ group). $\boldsymbol{B}$, This effect is illustrated in representative images of $\mathrm{CCR2}^{+}$and $\mathrm{MCH}^{+}$single-labeled neurons. $C$, Ethanol treatment increased the density of $\mathrm{CCR2}^{+} / \mathrm{MCH}^{+}$double-labeled neurons compared with control, and this effect is abrogated in the offspring by maternal injection of the CCR2 antagonist INCB3344. D, This effect of ethanol is illustrated in representative confocal images of $\mathrm{CCR2}^{+} / \mathrm{MCH}^{+}$neurons (arrows, yellow) that double-label $\mathrm{CCR2}^{+}$(red) and $\mathrm{MCH}^{+}$(green), showing few in the control group (left), many in the ethanol group (middle), and few in the ethanol + INCB3344 offspring (right). $\boldsymbol{E}$, Ethanol treatment increased $24 \mathrm{~h}$ ethanol drinking behavior in the adolescent offspring ( $n=10 /$ group), and this effect is blocked by maternal administration of the CCR2 antagonist. Scale bar, $200 \mu \mathrm{m}$. Data are mean \pm SEM. ${ }^{*} p<0.05$ versus control and versus ethanol + INCB3344.

\section{CCR2 receptor antagonism blocks stimulatory effects of maternal ethanol on CCR2/MCH neurons and behavior} This experiment directly tested in adolescent offspring, from pregnant rats administered the CCR2 receptor antagonist INCB3344 during ethanol exposure, a possible involvement of the endogenous CCR2 receptor in the stimulatory effects of maternal ethanol administration on the $\mathrm{CCR} 2^{+}$- and $\mathrm{MCH}^{+}-\mathrm{Co}^{-}$ expressing neurons in the $\mathrm{LH}$ and also on their ethanol drinking behavior. We examined female adolescent offspring from dams in the following four groups: isocaloric control + vehicle (control), ethanol + vehicle (ethanol), ethanol + INCB3344, and control + INCB3344. With measurements of single-labeled neu-

(Figure legend continued.) double-labeled neurons relative to total large $\mathrm{CCL}^{+}$or $\mathrm{MCH}^{+}$ single-labeled neurons. $\boldsymbol{H}$, Representative confocal images, illustrating mostly large $\mathrm{CCL}^{+}$ (green) and $\mathrm{MCH}^{+}$(red) neurons that become yellow/red or green/red when double-labeled, show few $\mathrm{CCL}^{+} / \mathrm{MCH}^{+}$neurons (arrow) in control offspring (left) and many $\mathrm{CCL2}{ }^{+} / \mathrm{MCH}^{+}$ neurons (arrow) in ethanol-treated offspring (middle), with those in the white square illustrated at higher magnification (right). While few small $\mathrm{CCL}^{+}{ }^{+}$cells were found to double-label CCR2 or MCH, the small $\mathrm{CCL}^{+}{ }^{+}$cells (arrowhead, green) were sometimes seen adjacent to or surrounding large $\mathrm{MCH}^{+}$neurons (arrow, red) as shown in at far right. Scale bars: $A, 100 \mu \mathrm{m}$; $\boldsymbol{B}-\boldsymbol{H}, 200 \mu \mathrm{m}$. Data are mean \pm SEM. ${ }^{*} p<0.05$ versus control. rons in the $\mathrm{LH}$, a one-way ANOVA revealed a significant main effect of treatment on the density of CCR $2^{+}\left(F_{(3,24)}=7.004, p=\right.$ $0.02)$ and $\mathrm{MCH}^{+}\left(F_{(3,24)}=40.356, p=0.001\right)$ neurons (Fig. $\left.9 A\right)$, as illustrated in the photomicrographs (Fig. $9 B$ ). Post hoc analyses showed that maternal ethanol administration compared with control significantly increased the density of single-labeled $\mathrm{CCR}^{+}(37 \%, p=0.004)$ and $\mathrm{MCH}^{+}(43 \%, p=0.000)$ neurons and that this stimulatory effect of ethanol was blocked by maternal administration of the CCR 2 antagonist. This is indicated by a significant decrease in the ethanol + INCB3344 compared with the ethanol group in their density of CCR ${ }^{+}(p=0.000)$ and $\mathrm{MCH}^{+}(p=0.000)$ neurons, reduced to the same level as those in the control group ( $p=0.756$ and $p=0.062$, respectively). With no differences detected between the control + INCB3344 and the control group in their density of CCR $2^{+}(p=0.746)$ and $\mathrm{MCH}^{+}(p=0.867)$ neurons, the antagonist alone was found to have no effect of its own on these LH neurons. Analyses via a one-way ANOVA of the CCR $2^{+} / \mathrm{MCH}^{+}$double-labeled neurons in the LH revealed similar results, with a significant main effect of treatment on their density relative to the total CCR2 ${ }^{+}\left(F_{(3,24)}=\right.$ 242.131, $p=0.001)$ and $\mathrm{MCH}^{+}\left(F_{(3,24)}=104.187, p=0.001\right)$ single-labeled neurons (Fig. $9 C$ ), as illustrated by the confocal 
images (Fig. 9D). Post hoc analyses showed a significant ethanolinduced increase versus control in the density of CCR $2^{+} / \mathrm{MCH}^{+}$ double-labeled neurons relative to total CCR2 ${ }^{+}(p=0.001)$ and $\mathrm{MCH}^{+}(p=0.001)$ single-labeled neurons, an effect not evident after administration of the CCR2 antagonist. This is indicated by a significant decrease $(p=0.001)$ in their density when comparing the ethanol + INCB3344 group with the ethanol group, which was reduced to the same level as the CCR2 ${ }^{+}$and $\mathrm{MCH}^{+}$ neurons in the control group ( $p=0.076$ and $p=0.063$, respectively). Comparisons between the control + INCB3344 and control offspring revealed no differences in their density of CCR $2{ }^{+} /$ $\mathrm{MCH}^{+}$neurons relative to total CCR2 ${ }^{+}(p=0.355)$ and $\mathrm{MCH}^{+}$ $(p=0.098)$ neurons, showing once again that the antagonist under control conditions had little effect of its own on the density of these double-labeled neurons.

In a separate set of pregnant rats, we conducted another experiment with administration of INCB3344 and similarly found this CCR2 antagonist to abrogate ethanol's effect on ethanol drinking in female offspring. Analysis via a one-way ANOVA revealed a significant main effect of maternal treatment on ethanol intake $\left(F_{(3,36)}=8.03, p=0.000\right.$; Fig. $\left.9 E\right)$. Post hoc analyses showed that, compared with the control group, maternal ethanol administration caused a significant increase in ethanol drinking $(80 \%, p=0.001)$, and administration of the CCR2 antagonist blocked this stimulatory effect of ethanol, as indicated by a significant decrease in drinking $(p=0.000)$ in the ethanol + INCB3344 group versus the ethanol group reduced to the same level as that detected in the control group ( $p=$ 0.552). Comparisons between the control + INCB3344 and control groups revealed no difference in their measure of ethanol intake $(p=0.766)$, showing the antagonist to have little impact of its own on this behavior. Together, these results with pharmacological antagonism of the CCR2 receptors during pregnancy show that the integrity of endogenous CCR2 is essential for the stimulatory effects of maternal ethanol administration on the $\mathrm{CCR} 2^{+}$and $\mathrm{MCH}^{+}$coexpressing neurons in the $\mathrm{LH}$ and also the ethanol drinking behavior of female adolescent offspring, with a further test required to determine whether it is also needed for the maternal ethanol-induced increase in anxiety.

\section{Discussion}

We demonstrate that maternal administration of ethanol, at a moderate dose $(2 \mathrm{~g} / \mathrm{kg} / \mathrm{d})$ for $5 \mathrm{~d}$, has strong effects on the CCL2/ CCR2 chemokine system in the LH of adolescent offspring. It stimulates expression of CCL2 as reported in the hippocampus and cortex (Drew et al., 2015; Terasaki and Schwarz, 2016) and CCR2 as shown in the hypothalamus (Chang et al., 2015) but not the hippocampus and cortex (Terasaki and Schwarz, 2016), and also increases the density of CCL2- and CCR2-labeled cells in the LH. Notably, these CCL2 cells, like CCR2 (Chang et al., 2015), are found to be predominantly neurons rather than glia, with almost all colocalizing NeuN but none colocalizing the astrocyte marker GFAP and microglia marker Iba-1. These effects on neuronal CCL2 and CCR2 in offspring brain, without changes in peripheral CCL2 in the dam, may reflect a lower-grade inflammation that contrasts with ethanol's stimulatory effects at higher doses $(6-13 \mathrm{~g} / \mathrm{kg} / \mathrm{d})$ on CCL2 in astrocytes and microglia in the brain (Shetty and Phillips, 1992; Kane et al., 2014; Drew et al., 2015) and CCL2 levels in the periphery (Crews et al., 2015). While confirming in adolescent offspring our finding in weanling rats that ethanol stimulates the expression and density of CCR2 neurons colocalizing MCH (Chang et al., 2015), we further demonstrate that maternal ethanol administration stimulates colocalization of CCL2 with MCH in the LH. This finding, together with in vitro evidence that CCL2 increases the density and expression of other peptide neurons (Poon et al., 2014) and the proliferation and differentiation of neural stem cells (Hong et al., 2015), led us to investigate whether maternal exposure to CCL2 also affects these $\mathrm{MCH}$ neurons in the offspring. We show that CCL2 administration at 4 or $8 \mu \mathrm{g} / \mathrm{kg} / \mathrm{d}$ for $5 \mathrm{~d}$ (E10-E15), like ethanol, has a stimulatory effect on CCR2 and MCH neurons in the LH and markedly increases percentage of CCR2 neurons that colocalize $\mathrm{MCH}$. This provides the first evidence that a chemokine, such as CCL2, which has a relatively short half-life but profound and long-lasting effects when administered peripherally (Thacker et al., 2009) or centrally (Selenica et al., 2013), can stimulate the fetal programming of a specific neuropeptide system when administered during pregnancy, suggesting that endogenous CCL2 may be involved in ethanol's stimulatory effects on neuronal development.

While little is known about how CCL2 functions to mediate these ethanol effects in utero, our results regarding the types of CCL2 cells stimulated by maternal ethanol exposure provide hints at possible mechanisms. They show that ethanol stimulates both large CCL2 neurons, which, like MCH neurons, are concentrated predominantly in the LH and colocalize CCR2 as well as $\mathrm{MCH}$, and small CCL2 neurons, possibly interneurons or small neurotransmitter neurons, which are scattered throughout the hypothalamus but in the LH lie immediately adjacent to and surround the large $\mathrm{MCH}$ neurons. These two distinct populations indicate that neuron-derived CCL2 may have two modes of action when stimulated by ethanol, perhaps involving autocrine/ paracrine mechanisms as described in vitro (He and Crews, 2008; Xie et al., 2016). In large neurons, CCL2 may act intracellularly through local CCR2 receptors to stimulate $\mathrm{MCH}$, whereas in small neurons, CCL2 may be released and act extracellularly to stimulate CCR2 receptors on nearby $\mathrm{MCH}$ neurons. The importance of CCR2 in mediating these actions of CCL2 when stimulated by ethanol is demonstrated by our finding that a CCR2 receptor antagonist INCB3344, administered to the dam during the $5 \mathrm{~d}$ of ethanol exposure, blocks ethanol's stimulatory effect on $\mathrm{MCH}$ neurons. While there are no prior studies involving administration of a CCR2 antagonist during pregnancy, injection of CCR2 antagonists in adult rodents is found to block peripheral effects of ethanol (Wang et al., 2012; Xu et al., 2016), and deletion of the CCR2 gene decreases ethanol's effects in utero on neuronal damage and inflammation in spinal cord (Ren et al., 2017), suggesting that a CCR2 antagonist provides one means of rescuing offspring from ethanol's stimulatory effects in utero on fetal programming.

In addition to ethanol's effects on neuronal development, our evidence suggests that this CCL2/CCR2 chemokine system together with $\mathrm{MCH}$ has a role in mediating ethanol's effects on the offspring's behavior. There are numerous studies positively linking CCL2 and CCR2 to excess ethanol drinking (Blednov et al., 2005; June et al., 2015; Valenta and Gonzales, 2016) and anxiety (Pascual et al., 2014; Sawicki et al., 2015) and also MCH to increased ethanol consumption (Duncan et al., 2005; Cippitelli et al., 2010; Morganstern et al., 2010b) and anxiety (Gonzalez et al., 1996; Borowsky et al., 2002; Smith et al., 2006), with MCH injection into LH found to stimulate drinking behavior in adult rats (Morganstern et al., 2010b). While confirming prior studies from this laboratory (Chang et al., 2015) and others (Carneiro et al., 
2005; March et al., 2009; Fabio et al., 2015) showing maternal ethanol administration to increase ethanol intake and anxiety in the offspring, our findings here provide the first evidence that maternal administration of CCL2 has similar behavioral effects to ethanol, suggesting that ethanol-induced fetal programming of this chemokine system in $\mathrm{LH}$ as it relates to local $\mathrm{MCH}$ neurons contributes to behavioral disturbances during adolescence when substance abuse strongly predicts later adult abuse and dependence (Anthony and Petronis, 1995). This idea receives further support from our finding that the $\mathrm{LH}$ is a major site where the large neurons expressing this chemokine, its receptor, and the neuropeptide are most heavily concentrated and highly responsive in utero to both ethanol and CCL2, which while altering behavior increase to $>90 \%$ the percentage of CCR2 and CCL2 neurons closely associated with $\mathrm{MCH}$ neurons. Our findings that both doses of CCL2, like ethanol, stimulate CCR2 and $\mathrm{MCH}$ neurons while increasing anxiety in the offspring and also ethanol consumption at the higher dose, support a close link between these neuronal and behavioral changes, with drinking behavior apparently requiring a somewhat higher level of neuroimmune stimulation during pregnancy to be produced.

Perhaps our most important finding is that the effects of maternal ethanol or CCL2 on fetal programming of these neuronal systems and behavior are sexually dimorphic, with female offspring consistently showing greater sensitivity than male offspring to both ethanol and chemokine stimulation. Our results demonstrate that females after in utero exposure to ethanol or CCL2 subsequently drink more ethanol, are more anxious, exhibit greater expression of CCR2 and $\mathrm{MCH}$, and have a higher density of $\mathrm{MCH}$ neurons that colocalize either CCL2 or CCR2 in the LH. These findings agree with the general notion that females and males are differentially affected by adolescent and adult exposure to ethanol, with females more vulnerable to its effects and exhibiting a greater increase in inflammatory mediators, along with more neuroinflammatory damage, neurodevelopmental dysfunction, and behavioral disturbances (Hommer et al., 2001; Squeglia et al., 2012; Alfonso-Loeches et al., 2013; Pascual et al., 2015). While the precise mechanisms underlying these sex differences remain to be characterized and could involve a stimulation of CCL2 expression and release by estrogen (Lengi et al., 2007), our results focus attention on large CCR2 neurons in the LH that colocalize $\mathrm{MCH}$ and are highly responsive to CCL2. They demonstrate that maternal administration of CCL2, like ethanol, produces in female offspring an unusually large increase in CCR2 expression and far greater increase in ethanol intake that is blocked by a CCR2 antagonist, suggesting that endogenous CCL2 is more functionally active in promoting drinking behavior in females. This idea, along with evidence that central CCL2 infusion stimulates ethanol intake (Valenta and Gonzales, 2016), receives direct support from a study showing deletion of the CCL2 gene to reduce ethanol consumption in females but not males (Blednov et al., 2005).

In conclusion, this study of a specific population of neurons densely concentrated in the LH provides new information on possible mechanisms through which the neuronal CCL2/CCR2 system, when stimulated in utero by ethanol at low to moderate doses, interacts positively with local $\mathrm{MCH}$ neurons to increase their density along with ethanol drinking behavior in adolescent offspring. It is notable that this positive association between neuronal chemokine and neuropeptide systems and ethanol intake, likely reflecting a state of low-grade inflammation as suggested for conditions of overeating and obesity (Weisberg et al., 2006;
Panee, 2012), differs markedly from the high-grade inflammation induced by LPS in adult rats, which is characterized by increased CCL2 in astrocytes and microglia along with sickness behavior, reduced appetite, and weight loss (Sens et al., 2017) and is generally stronger in males (Cai et al., 2016) and associated with a suppression of MCH (Le Thuc et al., 2016). The positive relationship described here, produced by in utero exposure to ethanol or CCL2 at doses having little effect on food intake or body weight, is consistently stronger in female offspring and accompanied by increased density of MCH neurons and excess ethanol drinking. The greater responsiveness to ethanol of neuronal CCL2/CCR2 signaling in LH of female adolescent offspring suggests one mechanism that may contribute to the higher levels of adolescent risk factors for alcohol use disorders described in women (Foster et al., 2015) and may be related to a significant positive effect of fetal alcohol exposure on the adolescent daughters' drinking in contrast to a slight negative effect on the sons' drinking (Griesler and Kandel, 1998).

\section{References}

Abrahao KP, Salinas AG, Lovinger DM (2017) Alcohol and the brain: neuronal molecular targets, synapses, and circuits. Neuron 96:1223-1238. CrossRef Medline

Adachi N, Suzuki S, Matsuoka H, Fushimi S, Ono J, Ohta KI, Hirai Y, Miki T, Koshimizu H (2018) Corticotropin-releasing hormone-binding protein is up-regulated by brain-derived neurotrophic factor and is secreted in an activity-dependent manner in rat cerebral cortical neurons. J Neurochem. Advance online publication. Retrieved Jan. 22, 2018. doi: 10.1111/jnc. 14310

Alati R, Al Mamun A, Williams GM, O'Callaghan M, Najman JM, Bor W (2006) In utero alcohol exposure and prediction of alcohol disorders in early adulthood: a birth cohort study. Arch Gen Psychiatry 63:1009-1016. CrossRef Medline

Alfonso-Loeches S, Pascual M, Guerri C (2013) Gender differences in alcohol-induced neurotoxicity and brain damage. Toxicology 311:27-34. CrossRef Medline

Anthony JC, Petronis KR (1995) Early-onset drug use and risk of later drug problems. Drug Alcohol Depend 40:9-15. CrossRef Medline

Baer JS, Sampson PD, Barr HM, Connor PD, Streissguth AP (2003) A 21year longitudinal analysis of the effects of prenatal alcohol exposure on young adult drinking. Arch Gen Psychiatry 60:377-385. CrossRef Medline

Banisadr G, Gosselin RD, Mechighel P, Kitabgi P, Rostène W, Parsadaniantz SM (2005) Highly regionalized neuronal expression of monocyte chemoattractant protein-1 (MCP-1/CCL2) in rat brain: evidence for its colocalization with neurotransmitters and neuropeptides. J Comp Neurol 489:275-292. CrossRef Medline

Barson JR, Karatayev O, Chang GQ, Johnson DF, Bocarsly ME, Hoebel BG, Leibowitz SF (2009) Positive relationship between dietary fat, ethanol intake, triglycerides, and hypothalamic peptides: counteraction by lipidlowering drugs. Alcohol 43:433-441. CrossRef Medline

Barson JR, Fagan SE, Chang GQ, Leibowitz SF (2013) Neurochemical heterogeneity of rats predicted by different measures to be high ethanol consumers. Alcohol Clin Exp Res 37 [Suppl. 1]:E141-E151.

Barson JR, Ho HT, Leibowitz SF (2015) Anterior thalamic paraventricular nucleus is involved in intermittent access ethanol drinking: role of orexin receptor 2. Addict Biol 20:469-481. CrossRef Medline

Bittencourt JC, Presse F, Arias C, Peto C, Vaughan J, Nahon JL Vale W, Sawchenko PE (1992) The melanin-concentrating hormone system of the rat brain: an immuno- and hybridization histochemical characterization. J Comp Neurol 319: 218-245. CrossRef Medline

Blednov YA, Bergeson SE, Walker D, Ferreira VM, Kuziel WA, Harris RA (2005) Perturbation of chemokine networks by gene deletion alters the reinforcing actions of ethanol. Behav Brain Res 165:110-125. CrossRef Medline

Borowsky B, Durkin MM, Ogozalek K, Marzabadi MR, DeLeon J, Lagu B, Heurich R, Lichtblau H, Shaposhnik Z, Daniewska I, Blackburn TP, Branchek TA, Gerald C, Vaysse PJ, Forray C (2002) Antidepressant, anxiolytic and anorectic effects of a melanin-concentrating hormone-1 receptor antagonist. Nat Med 8:825-830. CrossRef Medline 
Brischoux F, Fellmann D, Risold PY (2001) Ontogenetic development of the diencephalic MCH neurons: a hypothalamic ' $\mathrm{MCH}$ area' hypothesis. Eur J Neurosci 13:1733-1744. CrossRef Medline

Cai KC, van Mil S, Murray E, Mallet JF, Matar C, Ismail N (2016) Age and sex differences in immune response following LPS treatment in mice. Brain Behav Immun 58:327-337. CrossRef Medline

Carneiro LM, Diógenes JP, Vasconcelos SM, Aragão GF, Noronha EC, Gomes PB, Viana GS (2005) Behavioral and neurochemical effects on rat offspring after prenatal exposure to ethanol. Neurotoxicol Teratol 27:585592. CrossRef Medline

Cerri C, Genovesi S, Allegra M, Pistillo F, Püntener U, Guglielmotti A, Perry VH, Bozzi Y, Caleo M (2016) The chemokine CCL2 mediates the seizure-enhancing effects of systemic inflammation. J Neurosci 36:37773788. CrossRef Medline

Chang GQ, Gaysinskaya V, Karatayev O, Leibowitz SF (2008) Maternal high-fat diet and fetal programming: increased proliferation of hypothalamic peptide-producing neurons that increase risk for overeating and obesity. J Neurosci 28:12107-12119. CrossRef Medline

Chang GQ, Karatayev O, Liang SC, Barson JR, Leibowitz SF (2012) Prenatal ethanol exposure stimulates neurogenesis in hypothalamic and limbic peptide systems: possible mechanism for offspring ethanol overconsumption. Neuroscience 222:417-428. CrossRef Medline

Chang GQ, Karatayev O, Leibowitz SF (2013) Prenatal exposure to nicotine stimulates neurogenesis of orexigenic peptide-expressing neurons in hypothalamus and amygdala. J Neurosci 33:13600-13611. CrossRef Medline

Chang GQ, Karatayev O, Leibowitz SF (2015) Prenatal exposure to ethanol stimulates hypothalamic CCR2 chemokine receptor system: possible relation to increased density of orexigenic peptide neurons and ethanol drinking in adolescent offspring. Neuroscience 310:163-175. CrossRef Medline

Chotro MG, Arias C (2003) Prenatal exposure to ethanol increases ethanol consumption: a conditioned response? Alcohol 30:19-28. CrossRef Medline

Chu HX, Arumugam TV, Gelderblom M, Magnus T, Drummond GR, Sobey CG (2014) Role of CCR2 in inflammatory conditions of the central nervous system. Journal of Cerebral Blood Flow \& Metabolism 34:14251429. CrossRef Medline

Cippitelli A, Karlsson C, Shaw JL, Thorsell A, Gehlert DR, Heilig M (2010) Suppression of alcohol self-administration and reinstatement of alcohol seeking by melanin-concentrating hormone receptor 1 (MCH1-R) antagonism in Wistar rats. Psychopharmacology (Berl) 211:367-375. CrossRef Medline

Cornelius MD, De Genna NM, Goldschmidt L, Larkby C, Day NL (2016) Prenatal alcohol and other early childhood adverse exposures: direct and indirect pathways to adolescent drinking. Neurotoxicol Teratol 55:8-15. CrossRef Medline

Crews FT, Sarkar DK, Qin L, Zou J, Boyadjieva N, Vetreno RP (2015) Neuroimmune function and the consequences of alcohol exposure. Alcohol Res 37:331-341, 344-351. Medline

Crews FT, Lawrimore CJ, Walter TJ, Coleman LG Jr (2017) The role of neuroimmune signaling in alcoholism. Neuropharmacology 122:56-73. CrossRef Medline

Dansereau MA, Gosselin RD, Pohl M, Pommier B, Mechighel P, Mauborgne A, Rostene W, Kitabgi P, Beaudet N, Sarret P, Melik-Parsadaniantz S (2008) Spinal CCL2 pronociceptive action is no longer effective in CCR2 receptor antagonist-treated rats. J Neurochem 106:757-769. CrossRef Medline

Drew PD, Kane CJ (2014) Fetal alcohol spectrum disorders and neuroimmune changes. Int Rev Neurobiol 118:41-80. CrossRef Medline

Drew PD, Johnson JW, Douglas JC, Phelan KD, Kane CJ (2015) Pioglitazone blocks ethanol induction of microglial activation and immune responses in the hippocampus, cerebellum, and cerebral cortex in a mouse model of fetal alcohol spectrum disorders. Alcohol Clin Exp Res 39:445454. CrossRef Medline

Duncan EA, Proulx K, Woods SC (2005) Central administration of melanin-concentrating hormone increases alcohol and sucrose/quinine intake in rats. Alcohol Clin Exp Res 29:958-964. CrossRef Medline

Elibol-Can B, Dursun I, Telkes I, Kilic E, Canan S, Jakubowska-Dogru E (2014) Examination of age-dependent effects of fetal ethanol exposure on behavior, hippocampal cell counts, and doublecortin immunoreactivity in rats. Dev Neurobiol 74:498-513. CrossRef Medline
Fabio MC, Macchione AF, Nizhnikov ME, Pautassi RM (2015) Prenatal ethanol increases ethanol intake throughout adolescence, alters ethanolmediated aversive learning, and affects mu but not delta or kappa opioid receptor mRNA expression. Eur J Neurosci 41:1569-1579. CrossRef Medline

Foster KT, Hicks BM, Iacono WG, McGue M (2015) Gender differences in the structure of risk for alcohol use disorder in adolescence and young adulthood. Psychol Med 45:3047-3058. CrossRef Medline

Gillette R, Reilly MP, Topper VY, Thompson LM, Crews D, Gore AC (2017) Anxiety-like behaviors in adulthood are altered in male but not female rats exposed to low dosages of polychlorinated biphenyls in utero. Horm Behav 87:8-15. CrossRef Medline

Gonzalez MI, Vaziri S, Wilson CA (1996) Behavioral effects of alpha-MSH and $\mathrm{MCH}$ after central administration in the female rat. Peptides 17:171177. CrossRef Medline

González-Burgos I, Alejandre-Gómez M, Olvera-Cortés ME, Pérez-Vega MI, Evans S, Feria-Velasco A (2006) Prenatal-through-postnatal exposure to moderate levels of ethanol leads to damage on the hippocampal CA1 field of juvenile rats: a stereology and Golgi study. Neurosci Res 56:400408. CrossRef Medline

Greco T, Hovda DA, Prins ML (2015) Adolescent TBI-induced hypopituitarism causes sexual dysfunction in adult male rats. Dev Neurobiol 75: 193-202. CrossRef Medline

Griesler PC, Kandel DB (1998) The impact of maternal drinking during and after pregnancy on the drinking of adolescent offspring. J Stud Alcohol 59:292-304. CrossRef Medline

$\mathrm{He}$ J, Crews FT (2008) Increased MCP-1 and microglia in various regions of the human alcoholic brain. Exp Neurol 210:349-358. CrossRef Medline

Hellemans KG, Verma P, Yoon E, Yu WK, Young AH, Weinberg J (2010) Prenatal alcohol exposure and chronic mild stress differentially alter depressive- and anxiety-like behaviors in male and female offspring. Alcohol Clin Exp Res 34:633-645. CrossRef Medline

Hommer D, Momenan R, Kaiser E, Rawlings R (2001) Evidence for a gender-related effect of alcoholism on brain volumes. Am J Psychiatry 158:198-204. CrossRef Medline

Hong YR, Lee H, Park MH, Lee JK, Lee JY, Suh HD, Jeong MS, Bae JS, Jin HK (2015) CCL2 induces neural stem cell proliferation and neuronal differentiation in Niemann-Pick type C mice. J Vet Med Sci 77:693-699. CrossRef Medline

June HL, Liu J, Warnock KT, Bell KA, Balan I, Bollino D, Puche A, Aurelian L (2015) CRF-amplified neuronal TLR4/MCP-1 signaling regulates alcohol self-administration. Neuropsychopharmacology 40:1549 1559. CrossRef Medline

Kanari K, Kikusui T, Takeuchi Y, Mori Y (2005) Multidimensional structure of anxiety-related behavior in early-weaned rats. Behav Brain Res 156:45-52. CrossRef Medline

Kane CJ, Drew PD (2016) Inflammatory responses to alcohol in the CNS: nuclear receptors as potential therapeutics for alcohol-induced neuropathologies. J Leukoc Biol 100:951-959. CrossRef Medline

Kane CJ, Phelan KD, Douglas JC, Wagoner G, Johnson JW, Xu J, Drew PD (2013) Effects of ethanol on immune response in the brain: regionspecific changes in aged mice. J Neuroinflammation 10:66. CrossRef Medline

Kane CJ, Phelan KD, Douglas JC, Wagoner G, Johnson JW, Xu J, Phelan PS, Drew PD (2014) Effects of ethanol on immune response in the brain: region-specific changes in adolescent versus adult mice. Alcohol Clin Exp Res 38:384-391. CrossRef Medline

Lengi AJ, Phillips RA, Karpuzoglu E, Ahmed SA (2007) Estrogen selectively regulates chemokines in murine splenocytes. J Leukoc Biol 81:1065-1074. CrossRef Medline

Le Thuc O, Cansell C, Bourourou M, Denis RG, Stobbe K, Devaux N, Guyon A, Cazareth J, Heurteaux C, Rostène W, Luquet S, Blondeau N, Nahon JL, Rovère C (2016) Central CCL2 signaling onto MCH neurons mediates metabolic and behavioral adaptation to inflammation. EMBO Rep 17: 1738-1752. CrossRef Medline

Lin YL, Lin SY, Wang S (2012) Prenatal lipopolysaccharide exposure increases anxiety-like behaviors and enhances stress-induced corticosterone responses in adult rats. Brain Behav Immun 26:459-468. CrossRef Medline

Liu X, Lee JG, Yee SK, Bresee CJ, Poland RE, Pechnick RN (2004) Endotoxin exposure in utero increases ethanol consumption in adult male offspring. Neuroreport 15:203-206. CrossRef Medline 
Malone SM, McGue M, Iacono WG (2010) Mothers' maximum drinks ever consumed in 24 hours predicts mental health problems in adolescent offspring. J Child Psychol Psychiatry 51:1067-1075. CrossRef Medline

March SM, Abate P, Spear NE, Molina JC (2009) Fetal exposure to moderate ethanol doses: heightened operant responsiveness elicited by ethanolrelated reinforcers. Alcohol Clin Exp Res 33:1981-1993. CrossRef Medline

Morganstern I, Chang GQ, Karatayev O, Leibowitz SF (2010a) Increased orexin and melanin-concentrating hormone expression in the perifornical lateral hypothalamus of rats prone to overconsuming a fat-rich diet. Pharmacol Biochem Behav 96:413-422. CrossRef Medline

Morganstern I, Chang GQ, Chen YW, Barson JR, Zhiyu Y, Hoebel BG, Leibowitz SF (2010b) Role of melanin-concentrating hormone in the control of ethanol consumption: region-specific effects revealed by expression and injection studies. Physiol Behav 101:428-437. CrossRef Medline

Nanji AA, Jokelainen K, Fotouhinia M, Rahemtulla A, Thomas P, Tipoe GL, Su GL, Dannenberg AJ (2001) Increased severity of alcoholic liver injury in female rats: role of oxidative stress, endotoxin, and chemokines. Am J Physiol Gastrointest Liver Physiol 281:G1348G1356. CrossRef Medline

Oskvig DB, Elkahloun AG, Johnson KR, Phillips TM, Herkenham M (2012) Maternal immune activation by LPS selectively alters specific gene expression profiles of interneuron migration and oxidative stress in the fetus without triggering a fetal immune response. Brain Behav Immun 26:623634. CrossRef Medline

Pandey S, Badve PS, Curtis GR, Leibowitz SF, Barson JR (2017) Neurotensin in the posterior thalamic paraventricular nucleus: inhibitor of pharmacologically relevant ethanol drinking. Addict Biol. Advance online publication. Retrieved from September 6, 2007. doi.org/10.1111/adb.12546.

Panee J (2012) Monocyte chemoattractant protein 1 (MCP-1) in obesity and diabetes. Cytokine 60:1-12. CrossRef Medline

Pascual M, Pla A, Miñarro J, Guerri C (2014) Neuroimmune activation and myelin changes in adolescent rats exposed to high-dose alcohol and associated cognitive dysfunction: a review with reference to human adolescent drinking. Alcohol Alcohol 49:187-192. CrossRef Medline

Pascual M, Baliño P, Aragon CM, Guerri C (2015) Cytokines and chemokines as biomarkers of ethanol-induced neuroinflammation and anxiety-related behavior: role of TLR4 and TLR2. Neuropharmacology 89:352-359. CrossRef Medline

Patton GC, McMorris BJ, Toumbourou JW, Hemphill SA, Donath S, Catalano RF (2004) Puberty and the onset of substance use and abuse. Pediatrics 114:e300-e306. CrossRef Medline

Paxinos G, Watson C (2005) The rat brain in stereotaxic coordinates. San Diego: Elsevier Academic.

Poon K, Ho HT, Barson JR, Leibowitz SF (2014) Stimulatory role of the chemokine CCL2 in the migration and peptide expression of embryonic hypothalamic neurons. J Neurochem 131:509-520. CrossRef Medline

Poon K, Barson JR, Ho HT, Leibowitz SF (2016) Relationship of the chemokine, CXCL12, to effects of dietary fat on feeding-related behaviors and hypothalamic neuropeptide systems. Front Behav Neurosci 10:51. CrossRef Medline

Qiang M, Wang MW, Elberger AJ (2002) Second trimester prenatal alcohol exposure alters development of rat corpus callosum. Neurotoxicol Teratol 24:719-732. CrossRef Medline

Qin L, He J, Hanes RN, Pluzarev O, Hong JS, Crews FT (2008) Increased systemic and brain cytokine production and neuroinflammation by endotoxin following ethanol treatment. J Neuroinflammation 5:10. CrossRef Medline

Ramos A, Correia EC, Izídio GS, Brüske GR (2003) Genetic selection of two new rat lines displaying different levels of anxiety-related behaviors. Behav Genet 33:657-668. CrossRef Medline

Rankine EL, Hughes PM, Botham MS, Perry VH, Felton LM (2006) Brain cytokine synthesis induced by an intraparenchymal injection of LPS is reduced in MCP-1-deficient mice prior to leucocyte recruitment. Eur J Neurosci 24:77-86. CrossRef Medline

Ren Z, Wang X, Yang F, Xu M, Frank JA, Wang H, Wang S, Ke ZJ, Luo J (2017) Ethanol-induced damage to the developing spinal cord: the involvement of CCR2 signaling. Biochim Biophys Acta 1863:2746-2761. CrossRef Medline

Sawicki CM, McKim DB, Wohleb ES, Jarrett BL, Reader BF, Norden DM,
Godbout JP, Sheridan JF (2015) Social defeat promotes a reactive endothelium in a brain region-dependent manner with increased expression of key adhesion molecules, selectins and chemokines associated with the recruitment of myeloid cells to the brain. Neuroscience 302:151-164. CrossRef Medline

Selenica ML, Alvarez JA, Nash KR, Lee DC, Cao C, Lin X, Reid P, Mouton PR, Morgan D, Gordon MN (2013) Diverse activation of microglia by chemokine (C-C motif) ligand 2 overexpression in brain. J Neuroinflammation 10:86. CrossRef Medline

Sengupta P (2013) The laboratory rat: relating its age with human's. Int J Prev Med 4:624-630. Medline

Sens J, Schneider E, Mauch J, Schaffstein A, Mohamed S, Fasoli K, Saurine J, Britzolaki A, Thelen C, Pitychoutis PM (2017) Lipopolysaccharide administration induces sex-dependent behavioural and serotonergic neurochemical signatures in mice. Pharmacol Biochem Behav 153:168-181. CrossRef Medline

Shetty AK, Phillips DE (1992) Effects of prenatal ethanol exposure on the development of Bergmann glia and astrocytes in the rat cerebellum: an immunohistochemical study. J Comp Neurol 321:19-32. CrossRef Medline

Simms JA, Steensland P, Medina B, Abernathy KE, Chandler LJ, Wise R, Bartlett SE (2008) Intermittent access to $20 \%$ ethanol induces high ethanol consumption in Long-Evans and Wistar rats. Alcohol Clin Exp Res 32:1816-1823. CrossRef Medline

Skofitsch G, Jacobowitz DM, Zamir N (1985) Immunohistochemical localization of a melanin concentrating hormone-like peptide in the rat brain. Brain Res Bull 15:635-649. CrossRef Medline

Smith DG, Davis RJ, Rorick-Kehn L, Morin M, Witkin JM, McKinzie DL, Nomikos GG, Gehlert DR (2006) Melanin-concentrating hormone-1 receptor modulates neuroendocrine, behavioral, and corticolimbic neurochemical stress responses in mice. Neuropsychopharmacology 31: 1135-1145. CrossRef Medline

Spear LP, Varlinskaya EI (2010) Sensitivity to ethanol and other hedonic stimuli in an animal model of adolescence: implications for prevention science? Dev Psychobiol 52:236-243. CrossRef Medline

Squeglia LM, Sorg SF, Schweinsburg AD, Wetherill RR, Pulido C, Tapert SF (2012) Binge drinking differentially affects adolescent male and female brain morphometry. Psychopharmacology (Berl) 220:529-539. CrossRef Medline

Terasaki LS, Schwarz JM (2016) Effects of moderate prenatal alcohol exposure during early gestation in rats on inflammation across the maternalfetal-immune interface and later-life immune function in the offspring. J Neuroimmune Pharmacol 11:680-692. CrossRef Medline

Thacker MA, Clark AK, Bishop T, Grist J, Yip PK, Moon LD, Thompson SW, Marchand F, McMahon SB (2009) CCL2 is a key mediator of microglia activation in neuropathic pain states. Eur J Pain 13:263-272. CrossRef Medline

Valenta JP, Gonzales RA (2016) Chronic intracerebroventricular infusion of monocyte chemoattractant protein-1 leads to a persistent increase in sweetened ethanol consumption during operant self-administration but does not influence sucrose consumption in Long-Evans rats. Alcohol Clin Exp Res 40:187-195. CrossRef Medline

Van Steenwinckel J, Reaux-Le Goazigo A, Pommier B, Mauborgne A, Dansereau MA, Kitabgi P, Sarret P, Pohl M, Mélik Parsadaniantz S (2011) CCL2 released from neuronal synaptic vesicles in the spinal cord is a major mediator of local inflammation and pain after peripheral nerve injury. J Neurosci 31:5865-5875. CrossRef Medline

Wang S, Xu M, Li F, Wang X, Bower KA, Frank JA, Lu Y, Chen G, Zhang Z, Ke Z, Shi X, Luo J (2012) Ethanol promotes mammary tumor growth and angiogenesis: the involvement of chemoattractant factor MCP-1. Breast Cancer Res Treat 133:1037-1048. CrossRef Medline

Weisberg SP, Hunter D, Huber R, Lemieux J, Slaymaker S, Vaddi K, Charo I, Leibel RL, Ferrante AW Jr (2006) CCR2 modulates inflammatory and metabolic effects of high-fat feeding. J Clin Invest 116:115-124. CrossRef Medline

West NR, Hegazy AN, Owens BM, Bullers SJ, Linggi B, Buonocore S, Coccia M, Görtz D, This S, Stockenhuber K, Pott J, Friedrich M, Ryzhakov G, Baribaud F, Brodmerkel C, Cieluch C, Rahman N, Müller-Newen G, Owens RJ, Kühl AA, et al. (2017) Oncostatin M drives intestinal inflammation and predicts response to tumor necrosis factor-neutralizing 
therapy in patients with inflammatory bowel disease. Nat Med 23:579589. Medline

Witt ED (2007) Puberty, hormones, and sex differences in alcohol abuse and dependence. Neurotoxicol Teratol 29:81-95. CrossRef Medline

Xie J, Yang L, Tian L, Li W, Yang L, Li L (2016) Macrophage migration inhibitor factor upregulates MCP-1 expression in an autocrine manner in hepatocytes during acute mouse liver injury. Sci Rep 6:27665. CrossRef Medline

Xie RG, Gao YJ, Park CK, Lu N, Luo C, Wang WT, Wu SX, Ji RR (2018) Spinal CCL2 promotes central sensitization, long-term potentiation, and inflammatory pain via CCR2: further insights into molecular, synaptic, and cellular mechanisms. Neurosci Bull 34:13-21. CrossRef Medline
Xu M, Wang S, Qi Y, Chen L, Frank JA, Yang XH, Zhang Z, Shi X, Luo J (2016) Role of MCP-1 in alcohol-induced aggressiveness of colorectal cancer cells. Mol Carcinog 55:1002-1011. CrossRef Medline

Zhou Y, Sheets KG, Knott EJ, Regan CE Jr, Tuo J, Chan CC, Gordon WC, Bazan NG (2011) Cellular and 3D optical coherence tomography assessment during the initiation and progression of retinal degeneration in the $\mathrm{Ccl} 2 / \mathrm{Cx} 3 \mathrm{cr} 1$-deficient mouse. Exp Eye Res 93:636-648. CrossRef Medline

Ziogas DC, Karagiannis AK, Geiger BM, Gras-Miralles B, Najarian R, Reizes O, Fitzpatrick LR, Kokkotou E (2014) Inflammation-induced functional connectivity of melanin-concentrating hormone and IL-10. Peptides 55:58-64. CrossRef Medline 